Pontifícia Universidade $C_{\text {atólica }}$

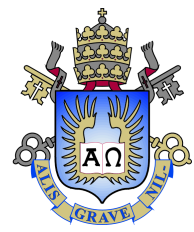

Roberto Hsu Rocha

Firms, Informality and Wage Inequality: Theory and Evidence from Brazil

Dissertação de Mestrado

Dissertation presented to the Programa de Pós-graduação em Economia of PUC-Rio in partial fulfillment of the requirements for the degree of Mestre em Economia.

Advisor: Prof. Gabriel Lopes Ulyssea

Rio de Janeiro

April 2018 


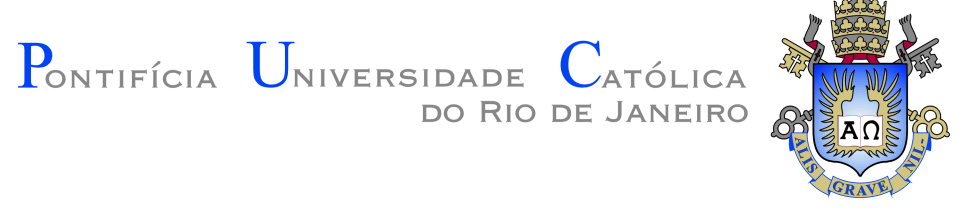

Roberto Hsu Rocha

\section{Firms, Informality and Wage Inequality: Theory and Evidence from Brazil}

Dissertation presented to the Programa de Pós-graduação em Economia of PUC-Rio in partial fulfillment of the requirements for the degree of Mestre em Economia. Approved by the undersigned Examination Committee.

Prof. Gabriel Lopes Ulyssea

Advisor

Departamento de Economia - PUC-Rio

Prof. Claudio Abramovay Ferraz do Amaral

Departamento de Economia - PUC-Rio

Dr. Miguel Nathan Foguel

Instituto de Pesquisa Econômica Aplicada - IPEA

Prof. Augusto Cesar Pinheiro da Silva

Vice Dean of Graduate Studies

Centro de Ciencias Sociais - PUC-Rio

Rio de Janeiro, April 2nd, 2018 
All rights reserved.

\section{Roberto Hsu Rocha}

B.A., Economics, Universidade de São Paulo (USP),2015

Bibliographic data

Rocha, Roberto Hsu

Firms, Informality and Wage Inequality: Theory and Evidence from Brazil / Roberto Hsu Rocha; advisor: Gabriel Lopes Ulyssea. - Rio de janeiro: PUC-Rio, Departamento de Economia, 2018.

v., 50 f: il. color. ; $30 \mathrm{~cm}$

Dissertação (mestrado) - Pontifícia Universidade Católica do Rio de Janeiro, Departamento de Economia.

Inclui bibliografia

1. Economia - Teses. 2. Economia - Teses. 3. Desigualdade de Salários;. 4. Firmas;. 5. Informalidade;. 6. Salário Mínimo;. I. Ulyssea, Gabriel. II. Pontifícia Universidade Católica do Rio de Janeiro. Departamento de Economia. III. Título. 


\section{Acknowledgments}

First I would like to thank my family for all the support given throughout my whole life.

I also want to thank the professors that guided me through the last years, specially my advisor prof. Gabriel Ulyssea, and prof. Claudio Ferraz.

Lastly, I would like to thank my colleagues in the last two and a half years, that are a great reason why I was able to do this project. 


\section{Abstract}

Rocha, Roberto Hsu; Ulyssea, Gabriel (Advisor). Firms, Informality and Wage Inequality: Theory and Evidence from Brazil. Rio de Janeiro, 2018. 50p. Dissertação de Mestrado - Departamento de Economia, Pontifícia Universidade Católica do Rio de Janeiro.

The labor market in Brazil had significant changes between 2003 and 2012. Wage inequality, informality and unemployment decreased while the real minimum wage rose. This paper has two major features. First, I propose a search and matching model with heterogeneous firms and workers that takes into account several attributes of the Brazilian labor market such as informality, unemployment, minimum wage, wage variance between and within firms and the educational composition of the workforce. Then, with an estimated model that fits important moments of the labor market in 2003, I make counterfactual exercises to quantify the determinants beneath the reduction of wage inequality. Results from the model suggest that changes in the real value of the minimum wage and the educational attainment of the workforce explain most of the reduction of wage inequality in the formal sector, but are more limited factors in the reduction of wage inequality in the whole economy.

\section{Keywords}

Wage Inequality; Firms; Informality; Minimum Wage; 


\section{Resumo}

Rocha, Roberto Hsu; Ulyssea, Gabriel. Firmas, Informalidade e desigualdade de salários: Teoria e Evidências para o Brasil. Rio de Janeiro, 2018. 50p. Dissertação de Mestrado - Departamento de Economia, Pontifícia Universidade Católica do Rio de Janeiro.

O Mercado de trabalho brasileiro passou por mudanças significativas entre 2003 e 2012. A desigualdade de salários, informalidade e desemprego caíram enquanto o salário mínimo real subiu. Evidências empíricas recentes sugerem que o papel das firmas foi importante nesses processos. Este artigo tem dois aspectos principais. Primeiro eu proponho um modelo de search e mathching com firmas e trabalhadores heterogêneos que leva em conta diversos atributos do mercado de trabalho brasileiro como informalidade, desemprego, salário mínimo e desigualdade de salários entre e intra firmas. Em seguida, com o modelo estimado que replica momentos importantes do mercado de trabalho em 2003, eu proponho exercícios contrafactuais para quantificar os determinantes por trás da redução da desigualdade de salários no Brasil. Os resultados do modelo sugerem que as mudanças no valor real do salário mínimo e da composição educacional da força de trabalho explicam grande parte da redução da desigualdade de salários no setor formal, mas são fatores mais limitados na redução da desigualdade de renda na economia como um todo.

\section{Palavras-chave}

Desigualdade de Salários; Firmas; Informalidade; Salário Mínimo; 


\section{Table of contents}

1 Introduction $\quad 11$

2 Data and Facts $\quad 15$

$\begin{array}{lll}2.0 .1 & \text { Data } & 15\end{array}$

$\begin{array}{lll}2.0 .2 & \text { Facts } & 16\end{array}$

3 Model $\quad 22$

3.0.1 Labor Markets 22

3.0.2 Firms' Problem 23

$\begin{array}{ll}3.0 .3 \text { Workers } & 25\end{array}$

3.0.4 Wages and Labor Demand 25

3.0.5 Minimum Wage 26

$\begin{array}{ll}3.0 .6 & \text { Equilibrium } \\ & 27\end{array}$

4 Calibration $\quad 29$

$\begin{array}{lll}\text { 4.0.1 } & \text { Functional Forms } & 29\end{array}$

$\begin{array}{lll}4.0 .2 & \text { Calibration } & 30\end{array}$

5 Counterfactual Exercises $\quad 34$

6 Conclusions $\quad 36$

$\begin{array}{ll}\text { Bibliography } & 37\end{array}$

A Two periods of reduction of Wage Inequality 40

B Solving the problem of the Firm 45

C Solving for the Wage Function $\quad 46$ 


\section{List of figures}

Figure 2.1 Unemployment and Informality between 2003 and 201216

$\begin{array}{lll}\text { Figure } 2.2 * & 16\end{array}$

Figure $2.3 * * 16$

Figure $2.4 * * 16$

Figure 2.5 Schooling Years of the Workforce in 2003 and $2012 \quad 17$

$\begin{array}{lll}\text { Figure } 2.6 * & 17\end{array}$

Figure 2.7 Minimum Wage Evolution from 2003 to $2012 \quad 18$

Figure $2.8 * * 18$

Figure 2.9 Wage Variance in the Economy from 2003 to $2012 \quad 18$

Figure $2.10 * \quad 18$

Figure 2.11 Evolution of Variance Between and Within Firms: 2003 - $2012 \quad 19$

Figure $2.12 * \quad 19$

Figure 2.13 Wage growth by percentile from 2003 to 2012

Figure $2.14 * \quad 21$

Figure A.1 Evolution of Variance Between and Within Firms: 1995 - $2012 \quad 40$

Figure A.2 Wage growth by percentile: 1995 to 2002 and 2003 to 201241

Figure A.3 * 41

Figure A.4 * 41

Figure A.5 Variance by firm size 1995-2002 42

Figure A.6 * 42

Figure A.7 * 42

Figure A.8 * 42

Figure A.9 * $\quad 42$

Figure A.10 * 42

Figure A.11 Wage growth by percentile for each firm size between 1995 and $2002 \quad 42$

Figure A.12* 42

Figure A.13* 42

Figure A.14* 42

Figure A.15* 42

Figure A.16* 42

Figure A.17 Variance by firm size 2003-2012 43

Figure A.18* 43

Figure A.19* 43

Figure A.20* $* 43$

Figure A. $21 *+43$

Figure A.22* 43

Figure A.23 Wage growth by percentile for each firm size between 2003 and $2012 \quad 43$

Figure A. $24 * * 43$

Figure A. $25 *+43$

Figure A.26* 43 
Figure A.27*

Figure A.28*

43

Figure A.29 Informality, Unemployment and Minimum Wage 44

Figure A. $30 *$

44

Figure A. $31 *$

44

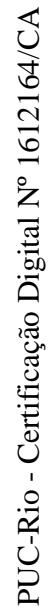




\section{List of tables}

Table 4.1 Directly Calibrated Parameters 30

Table 4.2 Results of the Calibration 32

Table 4.3 Model Fit 33

Table 5.1 Results of the Counterfactual Exercises 35 


\section{1 \\ Introduction}

Income inequality is currently on the core of economic and political discussions worldwide as it has grown constantly in most developed countries in the last decades ${ }^{1}$. In the midst of this debate, Brazil has emerged as a counter example to what has happened in the developed countries. Once considered one of the most unequal nations in the world, Brazil experienced a rapid fall in income inequality.

As most individuals earn the larger share of their income from the labor market, wages are the main determinant of income inequality in Brazil. This paper dives into the subject of wage inequality in Brazilian labor market and has two main features. First I propose a general equilibrium model with search and matching frictions and heterogeneous agents that embraces important aspects of the labor market such as the informal sector and labor regulations. Then, after I solve the model numerically calibrated to Brazilian data in 2003, I am able to do counterfactual exercises to quantify the importance of potential mechanisms behind the reduction of wage inequality in the economy from 2003 to $2012^{2}$.

Similar to most developing countries, Brazilian labor market is marked by an informal sector, which in Brazil employs over $30 \%$ of the workforce and represents more than $60 \%$ of firms. Since both sectors are not separate and workers often change between formality and informality, to understand the wage distribution in Brazil it is extremely relevant to contemplate both sectors of the economy. In my model, firms decide optimally to become formal or informal. Formal firms are subject to labor regulations such as taxes and minimum wage whereas informal ones face a cost of informality that is increasing in the number of workers hired. In equilibrium, highly productive firms will choose to be formal while the less productive ones become informal. The model doesn't account for the intensive margin of inequality as in (4), thus all workers in formal firms are formal workers.

Wage inequality arises in the model from differences in worker's skill but also from differences in firm's productivity, which makes it possible for

\footnotetext{
${ }^{1}(1),(2),(3)$ are some examples of discussions about income inequality worldwide.
}

${ }^{2}$ In Appendix A I discuss why I chose this specific period. 
workers with the same skill set to earn different wages according to the firm where they work at. This feature of the model is in line with a recent empirical literature that relates firms to inequality. Such literature has developed from the seminal article (5) (henceforth AKM) that uses French matched employeremployee data to decompose wages in firms and worker heterogeneity through a fixed effects model. They find that firms' fixed effects are relevant in the wage determination and in the variance of the wage distribution.

With the increasing availability of matched employer-employee data, several studies applied the AKM estimation to evaluate the role of firms in the dynamics of inequality. In Brazil's case, (6) applies the AKM estimation to investigate the decline in wage inequality. They estimate the model for different periods and their main result is the comparison between the estimations for 1996-2000 and 2008- 2012. Workers' fixed effects explain a bigger part of the total variance, but the changes in firms' fixed effects distribution between the periods accounts for a larger share of the change in total variance. These findings are similar for other countries. The same results are shown for Germany (7), Portugal (8) and the United States (10) (11), countries that experienced an increase in wage inequality in recent years. ${ }^{3}$

This empirical literature strongly suggests that workplace is important in the determination of earnings. In a perfectly competitive labor market this wouldn't be possible as an equilibrium result since the same skill set would be remunerated the same way across the market. To allow for different wages for similar workers, the model has search and matching frictions, that make workers unable to move between jobs instantaneously. Frictions are modelled in my framework according to (12) and jobs are created through a matching function that depends on the total number of vacancies and the measure of unemployed workers in the economy. There is no on-the-job search, thus to change between jobs a worker must first go through unemployment.

The framework I develop is intrinsically connected to the one in (13). Similar to their model, I use the structure from (14) that combines intra-firm bargaining as in (15) with search and matching frictions. Such structure also allows for diminishing returns and imperfect substitutability between types of workers. I use a set of labor regulations related to the one by (13) which allows me to characterize an equilibrium with an informal and a formal sector.

Despite having a similar decision of informality as in (13), my model produces a completely different result in terms of the wage distribution and the relation between firms and wage determination. In their framework workers with the same skill receive the same wage across firms, conditional on being

\footnotetext{
${ }^{3}$ For a complete review of this literature, see (9).
} 
in the same sector. This creates mass points in the distribution of wages, each point corresponding to a pair of skill and sector. Since in my model the productivity of the firm is also relevant to wage determination, the wages for each worker depend on the combination of skill, sector and the firm where he or she works.

Similar to (13) in my framework is possible to analyze aspects of the skill composition of the workforce and labor regulations. Specifically regarding labor regulations, one important aspect of my model is that I incorporate minimum wage to my analysis. The real value of the minimum wage rose considerably during the last decades in Brazil and is pointed out by some as the main reason behind the reduction of wage inequality (16) (6). (17) develop a wage posting structural model and estimate that $70 \%$ of the reduction of wage variance in the Brazilian formal sector is due to the rise of the minimum wage. Nevertheless, their analysis ignore the informal sector of the economy. Their wage posting model also doesn't allow for a deep analysis of the workforce composition as in their model different workers are perfect substitutes.

When I fit the model to the data, workers skill heterogeneity is matched with educational attainment. Brazil experienced a high increase in the average years of schooling in the last decades. Several studies have investigated the effects of this process on wage inequality. (18) argues through an structural model that the expansion of education had a huge impact on wage inequality, being responsible for nearly $80 \%$ of its decrease.

In the quantitative section, I analyze the impact of the expansion of education and the increase in the real value of the minimum wage on the reduction in wage variance in the Brazilian economy between 2003 and 2012. In order to quantify these effects, I calibrate my model to fit important moments of the labor market in 2003. Some parameters of the model are directly calibrated to values from the economy. Another set of parameters are calibrated by minimizing the distance from the moments generated by the model to the moments from the economy.

Using the calibrated model to make counterfactual exercises, I find that both changes in educational composition of the workforce and the rise in the minimum wage have effects on wage inequality. Keeping all other parameters constant, an increase in minimum wage in my simulations affected the wage variance in the formal sector specially through the wage variance between firms. It reduced the wage variance of the formal sector at 0.062 points, which represents $49 \%$ of the reduction in the period. At the same time it had limited effects on the wage variance in the whole economy ( $7 \%$ of the reduction in the period of interest). 
When I do the same kind of counterfactual simulation for the changes in education, I find that it had similar effects on the wage variance in the formal sector $(48 \%)$ but larger impacts on the wage variance in the whole economy ( $24 \%$ ). The simulations when I combine both changes suggest that the minimum wage and the educational changes had a large effect on the wage variance in the formal sector $(88 \%)$ but a less significant one in the wage variance in the whole economy $(27 \%)$.

The rest of this paper is organized in other five sections. Section 2 will show some stylized facts about wage inequality and labor markets in Brazil. Section 3 describes the theoretical model. Section 4 shows how I fit the model to Brazilian data. Section 5 presents the counterfactual exercises that were made while in section 6 are made some final considerations. 


\section{2 \\ Data and Facts}

In this section I provide some stylized facts about the reduction of inequality between 2003 and 2012. I will first describe briefly the data used, and then provide some descriptive statistics about the process.

\subsection{1}

Data

I use two different datasets, the Pesquisa Nacional por Amostra de Domicilios (PNAD) conducted by the Instituto Brasileiro de Geografia e Estatística (IBGE) and the Relação Anual de Informações Sociais (RAIS) conducted by the Brazilian Ministry of Labor (Ministério do Trabalho e Emprego, (MTE)).

The PNAD is a nation-wide household survey that provides several characteristics on the individual level. The PNAD is useful for me as it contains information of individuals in both formal and informal sectors. I will use the data from PNAD specially to create the moments used to calibrate the model.

The RAIS is a matched employer-employee dataset. All registered firms in Brazil must fill annually a survey from the MTE. Firms that don't fill the forms, or provide innacurate report can be fined by the government. RAIS dataset contains both worker' and firms' IDs which are unique and constant over time. Some statistics that will be shown in this section are only available to the formal sector because they need the link between employers and employees that is unique to the RAIS.

In both datasets I remove from the sample workers that are employed by the Public Administration. This is standard in the literature as it is assumed that the Public Sector not necessarily works to maximize its profits. Thus the wage determination process is significantly different from the one in the private sector. I also remove individuals that work less than 30 hours per week.

Combining both datasets is not ideal. Usually in household surveys, wage information is misreported on the top of the distribution. This may represent a smaller wage variance than the actual one. Meanwhile, the in the RAIS dataset, wages are reported by firms, and it is expected to have fewer mistakes in the top of the distribution. Nevertheless, using both datasets together is the only 
Figure 2.1: Unemployment and Informality between 2003 and 2012

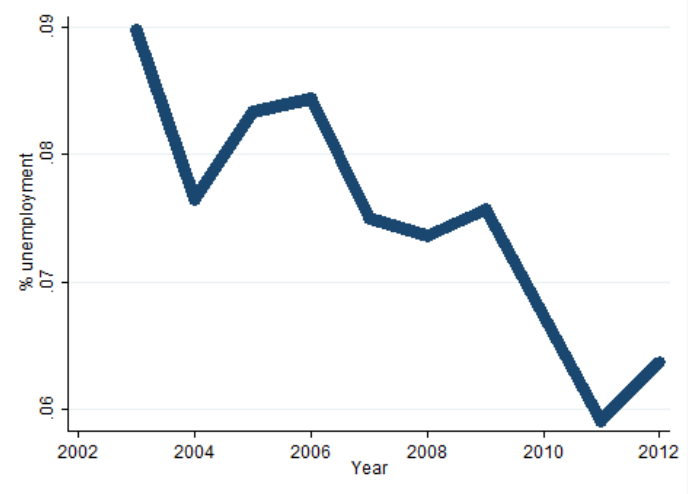

Figure 2.2: *

Desemprego

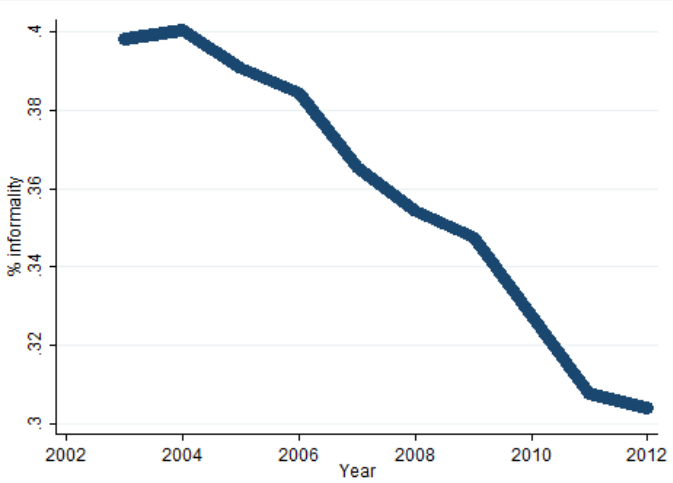

Figure 2.3: *

Informality

Figure 2.4: *

Notes: Informality and Unemployment are both calculated with the PNAD

way to investigate the informal sector and at the same time, have matched employer- employee information for at least one sector (the formal one).

\subsection{2}

Facts

In this subsection I show statistics about informality, unemployment, minimum wage and schooling years of the workforce. Then, I present some stylized facts about the reduction of wage inequality in Brazil.

The Brazilian labor market was marked by several changes between 2003 and 2012. Namely, informality and unemployment reduced significantly during the period. Throughout this paper I don't consider self employed individuals as informal workers. Rather, informal workers are the employees that work without having a formal contract with his or her employer. Informality in the data reduced nearly 6 p.p. during the period, going from $35.9 \%$ in 2003 to $30.4 \%$ in 2012 . Unemployed workers are defined as the workers that have searched for jobs in the respective year but are not employed at the time of the survey. Unemployment also reduced in the period, going from $15.65 \%$ to $9.66 \%$. Figure 2.1 illustrates these dynamics.

Next, I present the evolution of schooling years in the workforce and the minimum wage. These two processes will be analyzed in my counterfactual exercises, and are pointed out by several studies as the determinants of the reduction of wage inequality in Brazil.

The distribution of education in the workforce also changed significantly between 2003 and 2012. I divide the workforce into three different groups, based 
Figure 2.5: Schooling Years of the Workforce in 2003 and 2012

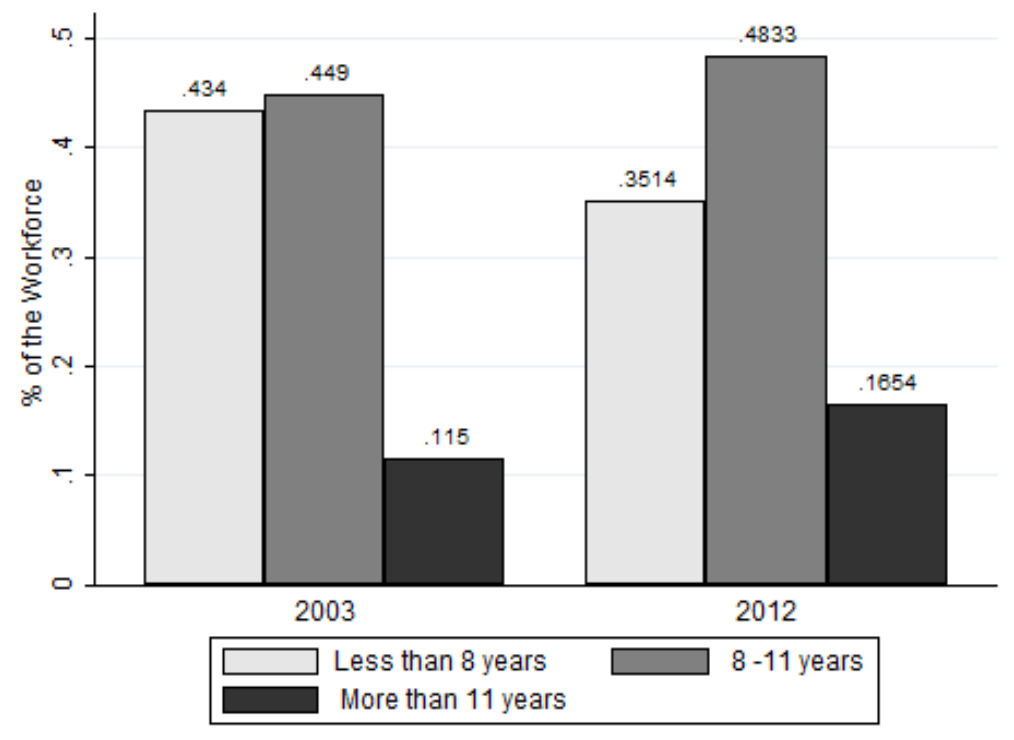

Figure 2.6: *

Notes: Share of education for each year is calculated with the PNAD

on their schooling years. These groups are the same ones that are matched to different types of workers in the model. The share of individuals with less than 8 years of schooling reduced considerably, while the other groups increased its share of the workforce. This is shown in figure 2.6.

Figure 2.7 shows the real values of the minimum wage in the period. As stated before, the real minimum wage increased $61 \%$ during the period. In the counterfactual exercises in section 5 , I replicate this increase using the model calibrated to the economy in 2003.

To illustrate the reduction of inequality in the whole economy, figure 2.9 shows the variance of the log of wages from 2003 to 2012. Wage variance decreased monotonically though the years from an initial level of 0.59 to 0.41 in 2012 .

The literature that links firms to inequality usually provides a series of statistical analysis to show the link between them. For this stylized facts, I will focus only on the formal sector, since it's necessary to have matched employer employee data. Following (19) and (10) one of the ways to analyze the firm side is by decomposing the total variance of wages into the variance between firms and within firms. Let $w_{i j t}$ be the wage earned by worker $i$ in the firm $j$ in the period $t$. A simple decomposition can be written as:

$$
w_{i j t}=\underbrace{\bar{w}_{t}}_{\text {economy average }}+\underbrace{\left(w_{i j t}-\bar{w}_{j t}\right)}_{\text {worker deviation }}+\underbrace{\left(\bar{w}_{j t}-\bar{w}_{t}\right)}_{\text {firm deviation }}
$$


Figure 2.7: Minimum Wage Evolution from 2003 to 2012

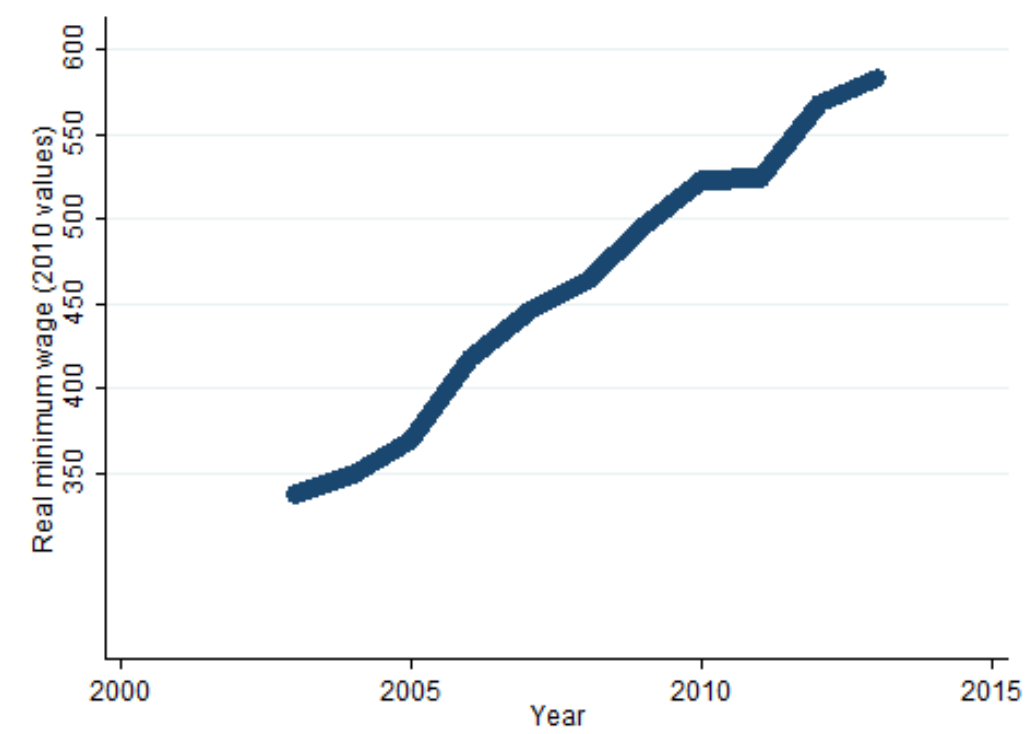

Figure 2.8: *

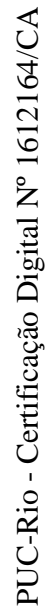

Notes: The figure plots the real value of the minimum wage in terms of 2010 Brazilian Reais.

Figure 2.9: Wage Variance in the Economy from 2003 to 2012

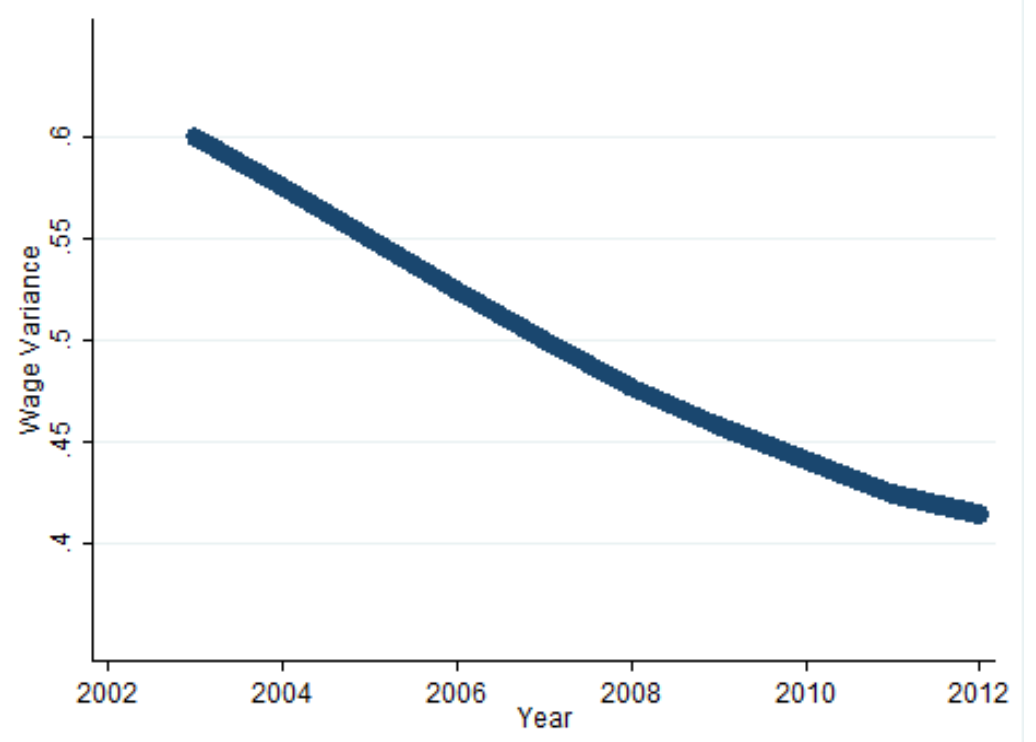

Figure 2.10: *

Notes: The figure plots the variance of wages aggregating both formal and informal sectors. This data is calculated with the PNAD. 
Figure 2.11: Evolution of Variance Between and Within Firms: 2003 - 2012

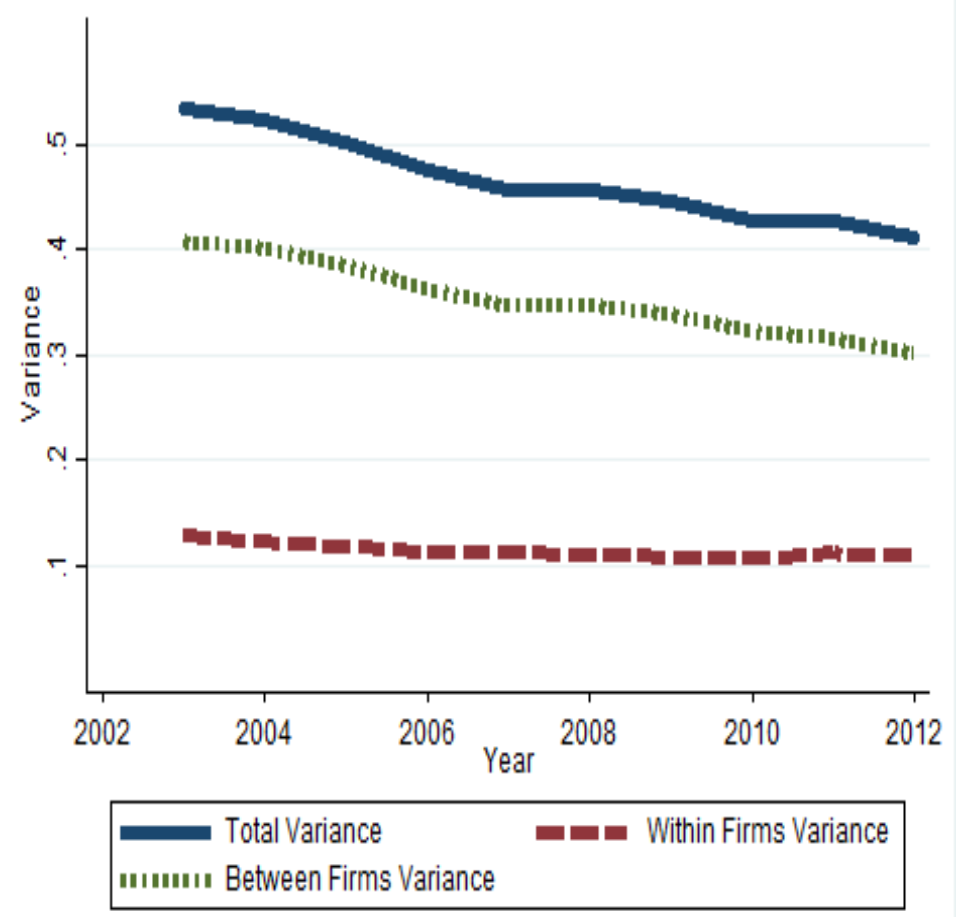

Figure 2.12: *

Notes: The statistics are build with RAIS data. It only contains information from the formal sector as to build this statistics it is necessary to have matched employer-employee data.

Where $\bar{w}_{t}$ is the average wage in the economy in period $t$ and $\bar{w}_{j t}$ is the average wage in firm $j$ in the period $t$. Applying the variance operator in both sides for a single period we get that:

$$
\operatorname{Var}\left(w_{i j}\right)=\operatorname{Var}\left(w_{i j}-\bar{w}_{j}\right)+\operatorname{Var}\left(\bar{w}_{j}-\bar{w}\right)+\underbrace{2 \operatorname{Cov}\left(w_{i j}-\bar{w}_{j}, \bar{w}_{j}-\bar{w}\right)}_{=0, \text { by construction }}
$$

Thus it is possible to write:

$$
\underbrace{\operatorname{Var}\left(w_{i j}\right)}_{\text {Total Variance }}=\underbrace{\overline{\operatorname{Var}\left(w_{i j} \mid i \in j\right)}}_{\text {Within firms variance }}+\underbrace{\operatorname{Var}\left(\bar{w}_{j}\right)}_{\text {Between firms variance }}
$$

Figure 2.11 shows the evolution of the total, between and within variance in the Brazilian labor market between 2003 and 2012. It is clear that the larger share of the reduction of wage inequality was due to between firms wage variance. This wage decomposition by itself doesn't imply that firms are paying their workers differently, nevertheless it is informative about a compression in between firms payment. 
Since inequality regards all the income distribution, sometimes the variance doesn't show all that happens in it. To further investigate what takes place in the whole distribution of wages, I use a variation of the graphical approach by (20) that is present in the article by (10).

To make the graphic shown in figure 2.13 I calculate the log real earnings for each percentile in both 2003 and 2012. Let $P_{t, x}$ denote the log earnings by the $x^{t h}$ percentile in the year $t$. The blue solid line in figure 2.13 plots the difference between 2012 and 2003 for all percentiles: $P_{2012, x}-P_{2003, x}$. The downward slope of the curve represents a decline in the overall wage inequality. It means that the lower percentiles of the distribution grew more than the higher ones. The curve is completely monotonic so this dynamic happens in all points of the wage distribution.

The blue solid line is the same graphic as in (20) but using Brazilian data. In turn, the red dashed line brings an addition to the analysis since it provides information about firms dynamics. This graphic is the same as the one shown by (10) to the U.S. but replicated to Brazilian data. In order to make the red dashed line, I divide the individuals among its percentile bins of the earnings distribution. For each bin, I then calculate the average of the mean log real wages at each individual's firm. This procedure is done for both 2003 and 2012. The red dashed line then plots the difference between 2012 and 2003 for each bin.

The gap between the blue solid line and the red dashed one represents the gains or losses that a particular demographic group had relative to the firm average for all employers. The graphic shows that the lower part of the distribution gains more relative to it's firms than the higher part. This is consistent with the decline in the between firms wage inequality shown in figure 2.11 .

The statistics shown in figures 2.11 and 2.13 together with the AKM estimations in (6) strongly suggest that firms are relevant in the determination of the wage distribution in Brazil. 
Figure 2.13: Wage growth by percentile from 2003 to 2012

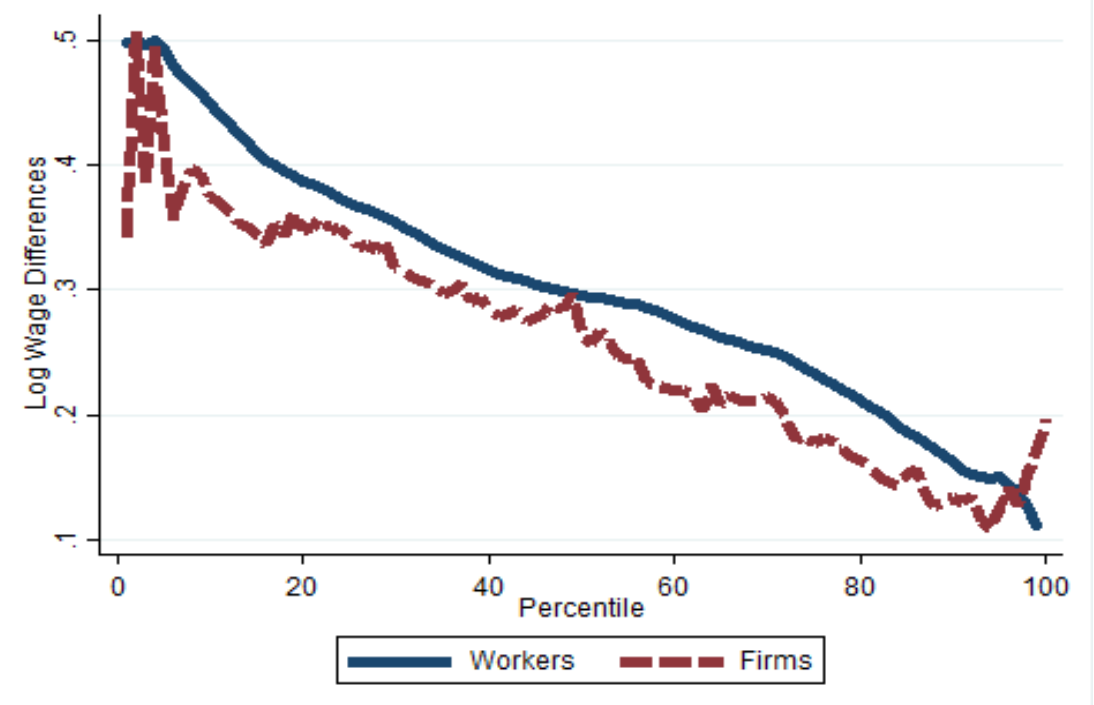

Figure 2.14: *

Notes: The statistics are build with RAIS data. It only contains information from the formal sector as to build this statistics it is necessary to have matched employer-employee data. 


\section{Model}

I develop a continuous time stationary equilibrium model with search and matching frictions capable of replicating key features of the Brazilian labor market such as workers and firms informality, within and between firms wage variance and minimum wage. Workers are divided into three types, each with mass $\eta_{i}, i \in\{1,2,3\}, \sum_{i} \eta_{i}=1$, and can only search for jobs on their respective market. There is a continuum of heterogeneous firms with mass $m$ that decide optimally to enter the formal or the informal sector. In the model, firms make only one formality decision and don't exit the market. All workers in formal firms are regarded as formal workers which makes me considered informality only on its extensive margin, thus I do not investigate the effects of the intensive margin of informality as proposed by (4).

The model draws the informality decisions from the framework developed by (13) but adds to it by being able to create wage variance within and between firms.

\subsection{1}

\section{Labor Markets}

Search frictions are modelled following (12). Due to labor market frictions, instead of choosing directly their labor inputs, firms post vacancies $\left(v_{i}\right)$ at each instant, paying a cost $\xi(v)$. The cost is increasing and convex on the number of vacancies posted at each instant ${ }^{1}$. The number of matches in the economy is given by a matching function $M\left(\mathcal{V}_{i}, u_{i}\right)$ where $\mathcal{V}_{i}$ and $u_{i}$ are the measures of vacancies and unemployed workers in the economy. $M\left(\mathcal{V}_{i}, u_{i}\right)$ follows the standard assumptions, as it is increasing on its arguments, concave, and has constant returns of scale. Defining $\theta_{i}=\frac{\mathcal{V}_{i}}{u_{i}}, q\left(\theta_{i}\right)$ gives a convenient form of writing instantaneous probability of filling a vacancy. The probability that an unemployed worker finds a job is given by $\theta_{i} q\left(\theta_{i}\right)$.

There are no distinctions in the search process between formal and informal firms. Therefore the aggregate of vacancies is the sum of all vacancies posted by formal and informal firms $\mathcal{V}_{i}=\mathcal{V}_{i}^{\text {for }}+\mathcal{V}_{i}^{\text {inf }}$. After a match is made,

${ }^{1}$ Convexity of posting costs follows a large body of literature on labor markets such as (21) and (17). 
the probability that the worker is matched with a formal firm is given by $\phi_{i}=\frac{\mathcal{V}_{i}^{f o r}}{\mathcal{V}_{i}}$. Henceforth, the index $i$ will denote worker types while $j$ will index firm sectors.

\subsection{2}

\section{Firms' Problem}

In short, the problem of the firm, consists on first optimally choosing its sector and then deciding on the number of vacancies posted at each moment. The problem can be solved recursively by first defining the value function at each sector and then choosing between being formal or informal. There are no idiosyncratic shocks nor uncertainty after the firm draws its productivity. Therefore, firms don't change between sectors once the formality decision is made.

Firms in both sectors are endowed with a production function $F(N ; p)$. The function is assumed to be continuous, twice differentiable and strictly concave. $N$ is the vector of labor inputs $n_{1}, n_{2}, n_{3} . p$ is the exogenous Hicksneutral productivity parameter that indexes firms. Once firms draw their productivity, it remains the same forever. The instantaneous profit of the formal and informal firms are given by:

$$
\begin{gathered}
\pi_{f o r}(N, V ; p)=F(N ; p)-\left[\sum_{i \in\{1,2,3\}}(1+\tau) n_{i} w_{i}^{\text {for }}(N)+\xi_{i}\left(v_{i}\right)\right]-F C_{\text {for }} \\
\pi_{\text {inf }}(N, V ; p)=F(N ; p)-\rho(N)-\left[\sum_{i \in\{1,2,3\}} n_{i} w_{i}^{i n f}(N)+\xi_{i}\left(v_{i}\right)\right]
\end{gathered}
$$

The profit functions show that formal firms have to pay taxes $\tau$ over their payroll. They also pay a fixed cost of operating. This fixed cost can be interpreted as cost of entry discounted over time summed to fixed bureaucratic costs that formal firms face at each moment. On the other hand, informal firms have an informality penalty $\rho(N)$ that is increasing and convex. The informality penalty is the same as in (22). It is interpreted as the increasing probability of being sanctioned by labor inspectors and the lack of access to public goods available to formal firms. The wage function $w_{i}^{j}(N)$ will be described in section 3.4 .

Every match in each sector is destroyed at an exogenous rate $s^{j}$, thus, there is a law of movement of labor quantities in each firm given by: 


$$
\dot{n}_{i}=v_{i} q\left(\theta_{i}\right)-s^{j} n_{i}, \quad \text { where } i \in\{1,2,3\} \quad \text { and } \quad j \in\{\text { formal,informal }\}
$$

This law of movements indicates that the instantaneous variation of each type of labor in a firm is given by the number of vacancies filled $v_{i} q\left(\theta_{i}\right)$ minus the number of jobs destroyed $s^{j} n_{i}$. Therefore, the problem of the firm is given by:

$$
\begin{gathered}
\Pi_{p}=\max _{j \in\{\text { for,inf }\}} \Pi_{p, j}(N), \quad \text { where } \\
\Pi_{p, j}(N)=\max _{V}\left(\frac{1}{1+r d t}\right)\left\{\pi_{j}(N, V ; p) d t+\Pi_{p, j}\left(N^{\prime}\right)\right\} \\
\text { s.t. } \quad n_{i}^{\prime}=n_{i}+\dot{n}_{i} d t=\left(1-s_{i}^{j} d t\right) n_{i}+v_{i} q\left(\theta_{i}\right)
\end{gathered}
$$

Where $r$ is the exogenous discount rate that is homogeneous in the economy.

Denoting the marginal value of an additional worker of type $i$ in a firm with productivity $p$ in sector $j$ by $J_{i}^{j}(N ; p)=\frac{\partial \Pi^{j}(N ; p)}{\partial n_{i}}$, the optimality conditions of the problem in steady state can be written $\mathrm{as}^{2}$ :

$$
\begin{gathered}
J_{i}^{f o r}(N ; p)=\frac{\xi_{i}^{\prime}\left(v_{i}\right)}{q\left(\theta_{i}\right)} \\
\left(r+s^{f o r}\right) J_{i}^{f o r}(N ; p)=\frac{\partial F(N ; p)}{\partial n_{i}}-(1+\tau)\left[w_{i}^{f o r}(N ; p)+\sum_{l \in\{1,2,3\}} n_{l} \frac{\partial w_{l}^{f o r}(.)}{\partial n_{i}}\right]
\end{gathered}
$$

The equations above characterize the solution for the formal sector, but the conditions are equivalent for formal and informal firms. Substituting $H(N ; p)=F(N ; p)-\rho(N)$ and $\tau=0$ in the equations above, the steady state solution to the problem of the informal firm is the same as the problem of the formal firm. The first equation comes from the first order condition of the firm in a steady state. It equals the value of a marginal worker to the expected cost of hiring an additional worker multiplied by the number of vacancies needed to hire one worker $\left(\frac{1}{q\left(\theta_{i}\right)}\right)$.

The second optimality condition comes from the envelop theorem as it equals the discounted marginal value of a worker with its benefits and costs. As hiring one additional worker diminishes the firms marginal productivity of all employed workers, in the marginal value of the additional worker there is the effect that it has on the wages of the other workers represented by $\sum_{l \in\{1,2,3\}} n_{l} \frac{\partial w_{l}^{\text {for }}(.)}{\partial n_{i}}$.

\footnotetext{
${ }^{2}$ The equations that define the optimal solution for the problem of the firm are detailed in Appendix B
} 


\subsection{3}

\section{Workers}

Workers are divided in three types and receive job offers only from their respective market. There is no on-the-job search in the economy, and the model doesn't consider effort on searching for jobs. Workers take the probability of finding a job $\theta_{i} q\left(\theta_{i}\right)$ and the value of being unemployed $U_{i}$ as given.

The flow equations that define the value of employment in both sectors are:

$$
\begin{aligned}
& r E_{i}^{f o r}(w)=w+s^{f o r}\left[U_{i}-E_{i}^{f o r}(w)\right] \\
& r E_{i}^{i n f}(w)=w+s^{\text {inf }}\left[U_{i}-E_{i}^{\text {inf }}(w)\right]
\end{aligned}
$$

It is assumed that workers derive utility directly from their wages and are risk neutral. The value of being unemployed $U_{i}$ is the same one on the utility flow of the formal and the informal worker. This value is the cost of opportunity of workers and is taken as given by firms and workers in the wage determination, but determined by the aggregate values of the economy in equilibrium. Differently from (13), I do not add mechanisms to generate compensating differentials in the model, such as unemployment benefits for the formal sector.

\subsection{4}

\section{Wages and Labor Demand}

Workers and firms share the rent created by the match through Nash bargaining. The model considers that workers and firms are allowed to renegotiate after the initial match. This assumption together with a production function with decreasing returns to scale lead to wage renegotiation as in (15). The solution to wage determination follows (14). The bargaining power of workers, given by parameter $\sigma_{i}$, differ across types but not across sectors.

The rent earned by a worker is $E_{i}^{j}(w)-U_{i}$ while for the firm is $J_{i}^{j}(N ; p)$. Thus, Nash bargaining implies that the wage function satisfies:

$$
\left(1-\sigma_{i}\right)\left[E_{i}^{j}\left(w_{i}^{p}(N ; p)\right)-U_{i}\right]=\sigma_{i} J_{i}^{j, p}(N)
$$

Adapting the solution of this non-linear system by (14) to our particular setting results in the following wage function for the formal sector ${ }^{3}$ :

$$
w_{i}(N ; p)=\frac{1-\sigma_{i}}{c_{i}} r\left(U_{i}\right)+\frac{1}{1+\tau} \int_{0}^{1} x^{\frac{1-\sigma}{\sigma(1+\tau)}} \frac{\partial F^{p}\left(A_{i}(x) N\right)}{\partial n_{i}} d x
$$

${ }^{3}$ The proof of this solution is in Appendix C 
Where $c_{i}=\left[\left(1-\sigma_{i}\right)+\sigma_{i}(1+\tau)\right]$ and $A_{i}(x)$ is a $3 \times 3$ diagonal matrix with each entry given by $x^{\frac{1-\sigma_{i}}{\sigma_{i}} \frac{\sigma_{k}}{1-\sigma_{k}}} \quad k \in\{1,2,3\}$.

The solution for the informal sector is similar. It arrives from equaling $F^{\text {inf }, p}\left(A_{i}(x) N\right)=F^{\text {for }, p}\left(A_{i}(x) N\right)-\rho(N)$ and $\tau=0$.

The wage function of each firm $p$ depends on the three inputs of labor. In a steady state, there is a direct relation between the number of workers in the firm and the number of vacancies posted. Given that in equilibrium $\dot{n}_{i}=0$, the number of vacancies posted by a firm $\mathrm{p}$ is defined implicitly by: $v_{i}^{p} q\left(\theta_{i}\right)=s^{j} n_{i}^{p} \rightarrow v_{i}^{p}=\frac{s^{j} n_{i}^{p}}{q\left(\theta_{i}\right)}$.

Now, going back to the Nash sharing rule and substituting the marginal value of a worker to the firm by the equation derived by the first order condition, one obtains:

$$
\left(1-\sigma_{i}\right)\left[E_{i}^{j}\left(w_{i}(N ; p)\right)-U_{i}\right]=\sigma_{i} J_{i}^{j, p}(N)=\sigma_{i} \underbrace{\frac{\xi^{\prime}\left(\frac{s_{i}^{j} n_{i}^{p}}{q\left(\theta_{i}\right)}\right)}{q\left(\theta_{i}\right)}}_{\text {Firms' F.O.C. }}
$$

Therefore, the firm adjusts its labor decisions in such a way that the system formed by the equation described above for the three types of workers is solved. Differently from (14) and (13), each firm will have it's own equilibrium wage for each kind of worker because of the convexity on the cost of posting vacancies. This feature provides between firms wage inequality in the model.

\subsection{5}

\section{Minimum Wage}

Adding minimum wage may change the solution to the problem of the firm if the wage determined according to the wage function for a given type is inferior to the minimum wage. This changes the labor demand for the given type where the minimum wage binds.

The demand for the other types of workers also change because when the minimum wage binds the wage of a given type of worker, it also affects the wage of the other types in the same firm. Since there is intra-firm bargaining, the marginal value of a given worker takes into account the effect that this worker has on the other workers' wages $\left(\sum_{l \in\{1,2,3\}} n_{l} \frac{\partial w_{l}(.)}{\partial n_{i}}\right)$. But in the case where the wage from one type is binding, the addition of a marginal worker from another type won't have any effect on the wage of the type binded, since it is fixed at the minimum wage.

More formally, given the marginal value added per worker in the formal sector $J_{i}^{f o r}(N ; p)$, 


$$
J_{i}^{f o r}(N ; p)=\frac{1}{\left(r+s^{\text {for }}\right)} \frac{\partial F^{j}(N ; p)}{\partial n_{i}}-(1+\tau)\left[w_{i}^{f o r}(N ; p)+\sum_{l \in\{1,2,3\}} n_{l} \frac{\partial w_{l}^{f o r}(.)}{\partial n_{i}}\right]
$$

when the minimum wage binds for type $l, \frac{\partial w_{l}^{f o r}(.)}{\partial n_{i}}=0$, which increases the value $J_{i}^{\text {for }}(N ; p)$.

This changes the solution to the wage function. For example, when the minimum wage binds for the type 1, type 2's wage will now be given by:

$w_{2}(N ; p)=\max \left\{w_{m i n}, \frac{1-\sigma_{2}}{c_{2}} r\left(U_{2}\right)+\frac{1}{1+\tau} \int_{0}^{1} x^{\frac{1-\sigma}{\sigma(1+\tau)}} \frac{\partial F^{p}\left(n_{1}, A_{2}(x) n_{2}, A_{2}(x) n_{3}\right)}{\partial n_{2}} d x\right\}$

In general equilibrium, if the minimum wage binds the wages of a single firm, the solution to all other firms will also change because of the adjusts in the value of unemployment $U_{i}$ and the tightness in the labor market $\theta_{i}$.

The general equilibrium effects of a binding minimum wage on the other firms equilibrium wages and labor demand is not clear. An increase in the minimum wage may increase $U_{i}$ by increasing the expected wage of workers, which in partial equilibrium would increase wages. But it may also reduce the demand for workers, increasing the labor market tightness therefore decreasing the probability of the worker finding an offer, resulting in a decrease of $U_{i}$ and thus reducing wages.

\subsection{6}

\section{Equilibrium}

In the stationary equilibrium it is necessary that $\theta_{i}$ and $U_{i}$ are consistent with the aggregate behavior of workers and firms. Thus far this behavior has been described taking these values as given. To define their stationary equilibrium, some conditions are necessary.

It is necessary to define the measure of workers of each type in each sector $\mathcal{N}_{i}^{j}$. Given the mass of firms $m$, the measure of workers in each sector is defined by:

$$
\mathcal{N}_{i}^{j}=m \int n_{i}^{p} \mathcal{I}(\text { Firm p chooses sector } \mathrm{j}) d G(p)
$$

Since in equilibrium, the number of vacancies posted by each firm is pinned down by the number of workers, the aggregate number of vacancies $\mathcal{V}_{i}^{j}$ can also be written as a function of the aggregate measure of workers: $\mathcal{V}_{i}^{j}=s^{j} \frac{\mathcal{N}_{i}^{j}}{q\left(\theta_{i}\right)}$. Now, it is possible to define the expressions that pin down $\theta_{i}$ : 


$$
\theta_{i}=\frac{\mathcal{V}_{i}}{u_{i}}=\frac{\frac{1}{q\left(\theta_{i}\right)}\left(s^{\text {for }} \mathcal{N}_{i}^{\text {for }}+s^{\text {inf }} \mathcal{N}_{i}^{\text {inf }}\right)}{\left(\eta_{i}-\mathcal{N}_{i}^{\text {for }}-\mathcal{N}_{i}^{\text {inf }}\right)}
$$

And the equilibrium value of being unemployed, is implicitly defined by the following flow equation:

$$
r U_{i}=\theta_{i} q\left(\theta_{i}\right)\left[\phi_{i} \mathbb{E}\left[E_{i}^{f o r}\left(w_{i}^{f o r, p}\right)\right]+\left(1-\phi_{i}\right) \mathbb{E}\left[E_{i}^{i n f, p}\left(w_{i}^{i n f, p}\right)\right]-U_{i}\right]
$$

The value of being unemployed $\left(U_{i}\right)$ is the expected value of finding a job and leaving unemployment. As there is no production while unemployed nor effort to search for jobs, there are no additional parameters in the value of being unemployed. The value of finding a job appears as an expectancy because it differs according to the firm that the worker matches.

With these objects defined, an equilibrium in the model is defined by the set of labor market tightness and values of unemployment for each type $\left\{\theta_{i}, U_{i}\right\}$ such that:

1. Wage functions are consistent with Nash sharing rule and firm's optimality;

2. Steady state conditions of sector size are satisfied;

3. Labor and formality decisions solve the recursive problem of the firm;

4. Labor market tightness and unemployment are consistent with aggregate behavior in the economy. 


\section{4}

\section{Calibration}

I calibrate the model to the Brazilian labor market in 2003. The moments of the economy that I aim to fit are obtained from the two different data sets that were described before. First, the RAIS is used to obtain moments of the formal sector. For the other moments, I use the PNAD, that embraces both formal and informal sectors of the economy.

The calibration is divided in two stages. First, I have a set of parameters that are directly mapped into parameters from the Brazilian economy economy. Second, I have a set of parameters that are determined through a minimum distance calibration, similar to the Simulated Method of Moments. Before explaining the calibration more carefully, it is necessary to describe some choices of functional forms to the model.

\subsection{1}

\section{Functional Forms}

To solve for equilibrium values in the model it is necessary to assume some functional forms. The production function will take a CES functional form:

$$
F(N ; p)=T F P * p *\left[\phi_{1} n_{1}^{\gamma}+\phi_{2} n_{2}^{\gamma}+\left(1-\phi_{1}-\phi_{2}\right) n_{3}^{\gamma}\right]^{\frac{\delta}{\gamma}}
$$

As stated in the model, informal and formal firms have the same production function which has five different parameters: $\left\{T F P, \phi_{1}, \phi_{2}, \gamma, \delta\right\} . \delta$ is necessarily less than 1, which guarantees the concave shape of the function. $\gamma \in(0,1)$ is also needed to assure that the labor inputs are substitutes. And $\phi_{1}, \phi_{2}$ are such that $1-\phi_{1}-\phi_{2}>0$.

The matching function $M\left(V_{i}, u_{i}\right)$ follows the standard assumptions of the literature. It is increasing on both inputs and has constant returns to scale. This function has only one parameter $(\alpha)$ and takes the following form:

$$
M\left(V_{i}^{f o r}, V_{i}^{\text {inf }}, u_{i}\right)=\frac{\left(V_{\text {inf }}+V_{\text {for }}\right) u_{i}}{\left(\left(V_{\text {inf }}+V_{\text {for }}\right)^{\alpha}+u_{i}^{\alpha}\right)^{\frac{1}{\alpha}}}
$$

The productivity parameter $p$ is assumed to be distributed accross firms 
Table 4.1: Directly Calibrated Parameters

\begin{tabular}{lcl}
\hline Parameters & Value & Source \\
\hline $\mathrm{r}$ & 0.008 & $(13)$ \\
$\tau$ & 0.73 & $(13)$ \\
{$\left[\eta_{1}, \eta_{2}, \eta_{3}\right]$} & {$[0.62,0.30,0.08]$} & $\mathrm{PNAD}$ \\
$m$ & 0.0905 & $(13)$ \\
$s_{\text {for }}$ & 0.030 & $(23)$ \\
$s_{\text {inf }}$ & 0.082 & $(23)$ \\
$\alpha$ & 0.5 & $(24)$ \\
$w_{\text {min }}$ & 1 & Numeraire \\
\hline
\end{tabular}

according to a Log-Normal distribution with mean zero and variance $\sigma_{p}$.

$$
G(p) \sim \log -\operatorname{Normal}\left(0, \sigma_{p}\right)
$$

Finally, the last two functions that need more structure are the cost of being an informal firm $(\rho(N))$ and the cost of posting vacancies $\left(\xi\left(v_{i}\right)\right)$. Both are assumed to be increasing and convex on their inputs. Their functional forms are assumed to be similar as $\rho(N)=\rho\left(n_{1}+n_{2}+n_{3}\right)^{1.5}$ and $\xi\left(v_{i}\right)=\xi\left(v_{i}\right)^{2}$. These two cost functions add two additional parameters to the model $(\{\rho, \xi\})$.

\subsection{2}

\section{Calibration}

I divide the total set of parameters in two subsets that will be calibrated differently. The first subset of parameters is $\Theta=\left\{r, \tau, \eta_{i}, m, s_{f o r}, s_{\text {inf }}, w_{\text {min }}\right\}$. Their values are shown in table 4.1.

The exogenous destruction rates for each sector $s^{j}$ are taken from (23) where the authors estimate the duration of employment spells in each sector. The payroll tax value, $\tau$, is the same as in (13) who in turn, built their calculation from the methodology by (25). Other parameters that are taken from (13) are the interest rate, $r$, and the mass of firms, $m$. Finally, the parameter of the matching function, $\alpha$, follows (24).

The minimum wage is the numeraire in my model. In the calibration its value is naturally one. When doing counterfactual exercises, I will change its value to replicate the real increase in the minimum wage observed in the economy.

A more detailed discussion is needed for the share of each type $\eta_{i}$. As the different types are understood as different skill sets of workers, I make a correspondence between types and educational attainment. I divide the economically active population in three groups according to schooling years. The share of each group accounts for $\eta_{i}$ when I solve the model. 
Type 1 corresponds to individuals with less than 8 years of schooling. In Brazil, having less than 8 years of schooling represents not finishing the elementary school ${ }^{1}$. The second group correspond to individuals with 8 to 11 years of schooling. This group embraces individuals that finished elementary school and high school. Finally, type 3 workers are corresponded to individuals that had educational levels higher than high school.

The choice for three types of workers in the model matches the dispersion of schooling years in Brazilian workforce. I face a trade-off between expanding the number of types in the model, which would increase the difficulty of numerically solving and calibrating the model, and working with only two types of workers, which would oversimplify the heterogeneity inside the groups of education. Three types of workers is a reasonable balance as it allows me not to ensemble workers with high discrepancy in schooling years and still have a reasonable numerical problem to solve.

The second subset of parameters is $\Psi=\left\{\xi, \rho, T F P, \delta, \gamma, \sigma_{i}, \phi_{1}, \phi_{2}, \sigma_{p}, F C_{\text {for }}\right\}$. The calibration of $\Psi$ is somewhat similar to a Simulated Method of Moments (SMM) estimation, but, contrary to SMM, it doesn't have an asymptotic theory to provide standard errors for the point estimates.

In this second stage, I define $\bar{\mu}$ as a vector of moments from the data. The list of moments chosen can be seen at table 4.3. They embrace relevant characteristics from the Brazilian labor market and the distribution of wages in the economy.

Aiming to replicate the wage distribution in the economy, I targeted six moments directly related to it. As explained before, to calculate the wage variance between firms it is necessary to have a matched employeremployee data set, which is only available to the formal sector of the Brazilian labor market. Therefore I chose to match the wage variance of the formal sector, its between firms variance and the variance in the whole economy. The three additional moments directly taken from the wage distributions are the differences between percentiles of the distribution. Those three were chosen as standard values used in the literature for measuring the dispersion of the distribution.

To explore the differences between types in the economy I target the wage differences between types 1 and 2 and types 1 and 3. As described above, each type is mapped to an level of educational attainment. I calculate in the data the average wage of each group of schooling years and the moments used are the differences in these averages.

\footnotetext{
${ }^{1}$ Beginning at 2010, Brazil's Ministry of Education determined that elementary school would be 9 years long. This change doesn't affect our analysis as the individuals that were affected wouldn't be at the labor market during the period studied in this paper.
} 
Table 4.2: Results of the Calibration

\begin{tabular}{lll}
\hline Parameter & & Value \\
\hline$\xi$ & Cost of Posting Vacancies & 0.2678 \\
$\rho$ & Cost of Informality & 0.0321 \\
$\sigma_{1}$ & Bargain Power - type 1 & 0.3894 \\
$\sigma_{2}$ & Bargain Power - type 2 & 0.4565 \\
$\sigma_{3}$ & Bargain Power - type 3 & 0.4785 \\
$\delta$ & Production Function & 0.7558 \\
$\gamma$ & Production Function & 0.7069 \\
$\mathrm{TFP}$ & Production Function & 11.904 \\
$\phi_{1}$ & Production Function & 0.3203 \\
$\phi_{2}$ & Production Function & 0.3348 \\
$F C_{\text {for }}$ & Fixed Cost of Being formal & 6.0855 \\
$\sigma_{p}$ & Variance - Distribution of Productivity & 0.8434 \\
\hline
\end{tabular}

Informality is included by matching the total share of informal workers in the economy, the share of informal firms and the difference between the average wage on each sector. As stated before, throughout the paper the share of informal workers do not include self-employed workers nor public servers. This statistic is calculated from the PNAD dataset. The share of informal firms is taken from (4) and was originally calculated from the Economia Informal Urbana (ECINF) dataset ${ }^{2}$. As the model doesn't encompass the intensive margin of informality, the share of informal firms is an important moment to target in the calibration.

Once with the vector of moments from the data $\bar{\mu}$, I generate $\mu(\Psi, \Theta)$, a function of the parameters that provide the equivalent in the model to the moments in vector $\bar{\mu}$. I obtain a set of calibrated parameters $\hat{\Psi}$ (shown in table $4.2)$ as the result of the following minimization:

$$
\hat{\Psi}=\underset{\Psi}{\operatorname{argmin}}[\mu(\Psi ; \Theta)-\bar{\mu}]^{\prime}[\mu(\Psi ; \Theta)-\bar{\mu}]
$$

The fit of the model to the data can be seen at table 4.3. The model fits reasonably well all the targeted moments, specially the ones that concern the wage distribution. Wage differences between sectors is the moment that relies further from the data. This arises because the model is not able to produce an overlap of firm productivity between sectors as in (4) and (22). As firm productivity is related to wage determination in the model, the wage differences are not fitted extremelly well either.

\footnotetext{
${ }^{2}$ The ECINF was a survey of Informal Urban Economy conducted by the IBGE in 2003 and targeted small firms, both from the formal and informal sectors.
} 
Table 4.3: Model Fit

\begin{tabular}{lrc}
\hline Moments & Model & Data \\
\hline Share of Informal Firms & 0.7289 & 0.6980 \\
Between Firms Var. (Formal) & 0.4003 & 0.4080 \\
Formal Sector Var. & 0.5389 & 0.5360 \\
Economy Var. & 0.5836 & 0.5994 \\
Unemployment & 0.1619 & 0.1565 \\
Informality & 0.3427 & 0.3592 \\
Wage Dif. Formal - Informal & 0.8145 & 0.6357 \\
Wage Dif. Type 1 and 2 & 0.2950 & 0.3770 \\
Wage Dif. Type 1 and 3 & 1.2978 & 1.2079 \\
Dif. Pct 90 - Pct 10 & 1.7640 & 1.7047 \\
Dif. Pct 90 - Pct 50 & 1.1275 & 1.0369 \\
Dif. Pct 50 - Pct 10 & 0.6365 & 0.6678 \\
\hline
\end{tabular}




\section{5}

\section{Counterfactual Exercises}

I use the calibrated model to do counterfactual exercises that allow me to quantify the effects of the changes in the educational composition of the workforce and the rise in the real value of the minimum wage on the wage distribution. The results of the exercises are shown in table 5.1

As described in the section 2, the real minimum wage rose sharply between 2003 and 2012. Its nominal value went from 240 Brazilian Reais in 2003 to 622 in 2012. Adjusted by the inflation in this period, this represented a real increase of $61 \%$ in the minimum wage. I replicate this same increase in the model changing the value of the $w_{\min }$ parameter. The results of an increase in the minimum wage are shown in column 2 of table 5.1.

The results from the model initially suggest that minimum wage was an important factor in the decrease of inequality in the formal sector. Specifically, it represented a great part of the reduction in between firms wage variance in the formal sector, in line with what is suggested by (6). In turn, minimum wage didn't have a large effect on wage variance in the whole economy. Despite its effects on wage variance, simulations from the model show that the increase of the minimum wage is not consistent with what happened to unemployment and informality. Table 5.1 shows that it increased informality and unemployment, going on the opposite direction to what happened in the Brazilian economy.

Changes in education of the workforce were simulated in the model by changing the share of workers from each type $\eta_{i}$. They had similar results on the wage variance in the formal sector as the minimum wage, but smaller ones in between firms wage variance. Nevertheless, it impacted more on the total wage variance of the economy, representing almost a quarter of the total reduction in my estimates. Even though this changes do not explain the reduction of informality and unemployment, they also do not contribute in the opposite direction as the increases in minimum wage.

Combining the increase in the minimum wage with the changes in education in the model generates the results in column 4. The aftermath is not a mere sum of the two separate effects, as in general equilibrium one change affects the magnitude of the other. As the share of workers from type 1 reduces, the share of workers that have their wage binding by the minimum 
Table 5.1: Results of the Counterfactual Exercises

\begin{tabular}{lcccc}
\hline Changes in & Data & \multicolumn{3}{c}{ Model } \\
\cline { 3 - 5 } Outcome & $2012-2003$ & Minimum Wage & Education & Both \\
& $(1)$ & $(2)$ & $(3)$ & $(4)$ \\
\hline \multirow{2}{*}{ Btw. Firms Wage Var. (Formal) } & -0.1065 & -0.0790 & -0.0273 & -0.0941 \\
& & $(74 \%)$ & $(26 \%)$ & $(88 \%)$ \\
Wage Var. in the Formal Sector & -0.1248 & -0.0620 & -0.0599 & -0.1110 \\
& & $(49 \%)$ & $(48 \%)$ & $(89 \%)$ \\
Total Wage Variance & -0.1678 & -0.0107 & -0.0408 & -0.0460 \\
& & $(7 \%)$ & $(24 \%)$ & $(27 \%)$ \\
Informality & & & & \\
& -0.055 & 0.0632 & 0.0008 & 0.0664 \\
Unemployment & & $(-114 \%)$ & $(-1.4 \%)$ & $(-120 \%)$ \\
& -0.0599 & 0.0106 & -0.0033 & 0.0089 \\
& & $(-17 \%)$ & $(6 \%)$ & $(-16 \%)$
\end{tabular}

Notes: The values under parenthesis represents the percentage of the variation in the data that is explained by the respective counterfactual exercise. The negative sign inside the parenthesis represents that the results from the simulation went in the opposite direction from the data.

wage reduces, since it affects mainly individuals with lower skills in the model. The results in column 4 suggest that the combination between both education and minimum wage explains almost all the reduction of wage inequality in the formal sector, but the same thing doesn't apply for the wage variance in the whole economy. The results in column 4 also suggest that changes in the schooling years of the workforce are not able to compensate the effects of the minimum wage on informality and unemployment. 


\section{6 \\ Conclusions}

This paper investigates the subject of wage inequality in Brazil. It adds to the literature by providing a new theoretical framework to study the subject that replicates important aspects of Brazilian labor market such as informality and the minimum wage. Wages in the model are determined not only by worker's skill and firm's sector but also by firm's productivity, replicating an important finding that is highlighted by a recent literature.

The model is able to replicate the Brazilian labor market in 2003, which allows me to do counterfactual exercises with two possible determinants of the reduction in wage inequality; the educational composition of the workforce, and the increases in the real value of the minimum wage. Despite having effects on the wage variance of the formal sector, increases in the minimum wage are not consistent with the dynamics of informality and unemployment that occurred in the period of my analysis in the Brazilian labor market. In turn, the model suggests that changes in the educational composition of the workforce were relevant in the reduction of inequality and didn't increase informality and unemployment as the minimum wage did.

Additional exercises could be done with the calibrated model, specially to further investigate the wage variance in the whole economy. Despite shedding light upon the dynamics between informality and formality in the determination of the wage distribution, further research could be done in this topic using the framework developed here by exploring more changes in labor regulations such as an increase in the cost of being informal or reduction in taxes and fixed costs of being a formal firm. 


\section{Bibliography}

[1] ATKINSON, A. B.; BOURGUIGNON, F.. Handbook of income distribution. Elsevier, 2014.

[2] PIKETTY, T.; SAEZ, E.. Income inequality in the united states, 1913-1998. The Quarterly journal of economics, 118(1):1-41, 2003.

[3] PIKETTY, T.. Capital in the 21st century. 2014.

[4] ULYSSEA, G.. Firms, informality and development: Theory and evidence from brazil. American Economic Review, 2018.

[5] ABOWD, J. M.; KRAMARZ, F. ; MARGOLIS, D. N.. High wage workers and high wage firms. Econometrica, 67(2):251-333, 1999.

[6] AlvareZ, J.; BenguriA, F.; ENGBOM, N. ; MOSER, C.. Firms and the decline of earnings inequality in brazil. Technical report, Working paper, 2018.

[7] CARD, D.; HEINING, J. ; KLINE, P.. Workplace heterogeneity and the rise of west german wage inequality. The Quarterly Journal of Economics, 128(3):967-1015, 2013.

[8] CARD, D.; CARDOSO, A. R. ; KLINE, P.. Bargaining, sorting, and the gender wage gap: Quantifying the impact of firms on the relative pay of women. The Quarterly Journal of Economics, 131(2):633-686, 2016.

[9] CARD, D.; CARDOSO, A. R.; HEINING, J. ; KLINE, P.. Firms and labor market inequality: Evidence and some theory. Technical report, National Bureau of Economic Research, 2016.

[10] SONG, J.; PRICE, D. J.; GUVENEN, F.; BLOOM, N. ; VON WACHTER, T.. Firming up inequality. Technical report, National Bureau of Economic Research, 2015.

[11] BARTH, E.; BRYSON, A.; DAVIS, J. C. ; FREEMAN, R.. It's where you work: Increases in earnings dispersion across establishments and individuals in the us. Technical report, National Bureau of Economic Research, 2014. 
[12] PISSARIDES, C. A.. Equilibrium unemployment theory. MIT press, 2000.

[13] HAANWINCKEL, D.; SOARES, R. R.. Workforce composition, productivity, and labor regulations in a compensating differentials theory of informality. 2016.

[14] CAHUC, P.; MARQUE, F. ; WASMER, E.. A theory of wages and labor demand with intra-firm bargaining and matching frictions. International Economic Review, 49(3):943-972, 2008.

[15] STOLE, L. A.; ZWIEBEL, J.. Intra-firm bargaining under nonbinding contracts. The Review of Economic Studies, 63(3):375-410, 1996.

[16] KOMATSU, B.; MENEZES-FILHO, N.. Does the rise of the minimum wage explain the fall of wage inequality in brazil? 2015.

[17] ENGBOM, N.; MOSER, C.. Earnings inequality and the minimum wage: Evidence from brazil. World, 2016.

[18] JAUME, D.. The labor market effects of an educational expansion. a theoretical model with applications to brazil. Technical report, Job Market Papers, 2017.

[19] FORTIN, N.; LEMIEUX, T. ; FIRPO, S.. Decomposition methods in economics. Handbook of labor economics, 4:1-102, 2011.

[20] JUHN, C.; MURPHY, K. M. ; PIERCE, B.. Wage inequality and the rise in returns to skill. Journal of political Economy, 101(3):410-442, 1993.

[21] KAAS, L.; KIRCHER, P.. Efficient firm dynamics in a frictional labor market. The American Economic Review, 105(10):3030-3060, 2015.

[22] MEGHIR, C.; NARITA, R. ; ROBIN, J.-M.. Wages and informality in developing countries. The American Economic Review, 105(4):15091546, 2015.

[23] GONZAGA, G.; MALONEY, W. F. ; MIZALA, A.. Labor turnover and labor legislation in brazil [with comments]. Economia, 4(1):165-222, 2003.

[24] ULYSSEA, G.. Regulation of entry, labor market institutions and the informal sector. Journal of Development Economics, 91(1):87-99, 2010. 
[25] SOUZA, A. P.; FIRPO, S. P.; PONCZEK, V.; ZYLBERSTAJN, E. ; RIBEIRO, F.. Custo do trabalho no brasil: Proposta de uma nova metodologia de mensuração. FGV/EESP, 2012.

[26] AUTOR, D. H.; KATZ, L. F. ; KEARNEY, M. S.. Trends in us wage inequality: Revising the revisionists. The Review of economics and statistics, 90(2):300-323, 2008.

[27] ACEMOGLU, D.; AUTOR, D.. Skills, tasks and technologies: Implications for employment and earnings. Handbook of labor economics, 4:1043-1171, 2011. 
A

\section{Two periods of reduction of Wage Inequality}

Several papers analyze the reduction of wage inequality from 1995 to 2012 (6) (18) (17). Wage inequality has fallen since 1995, but a more careful look suggests that the fall in wage variance wasn't a homogeneous process. Rather, it consisted of two different processes that followed each other throughout the years, the first one that goes from 1995 to 2002, and the following one from 2003 to 2012. In this section of the appendix I provide additional evidence that in fact the reduction of inequality can be divided in this two different periods.

First, figure A.1 replicate the same trends that figure 2.11. It shows that the wage inequality reduced during the whole period, and reinforces the importance of between firms wage variance not only in the trends, but also its level, as it represents a great share of the total variance in the formal sector of the economy.

But using the same methodology as figure 2.13, but dividing the period between 1995 and 2012, it is possible to see a clear difference between both periods. Between 1995 and 2002, the wage variance diminishes because the wages in the lower part of the distribution grew relatively, but as figure A.2 shows, in the period the top of the wage distribution grew relative to the middle part. This dynamic is similar to the polarization process that happened in the

Figure A.1: Evolution of Variance Between and Within Firms: 1995 - 2012

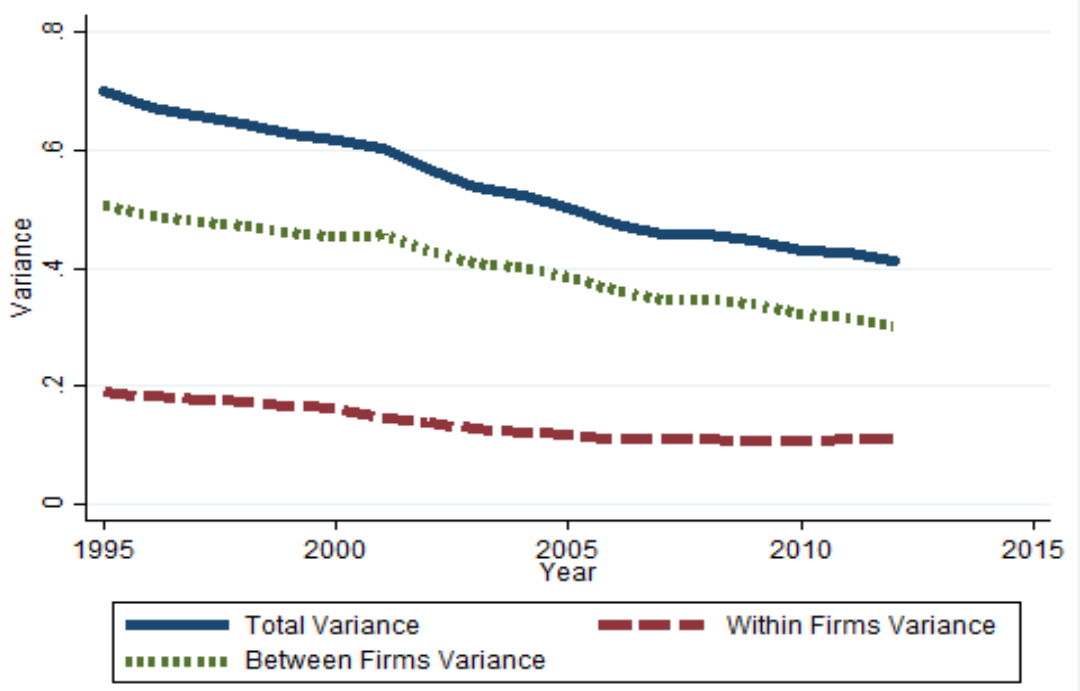


Figure A.2: Wage growth by percentile: 1995 to 2002 and 2003 to 2012

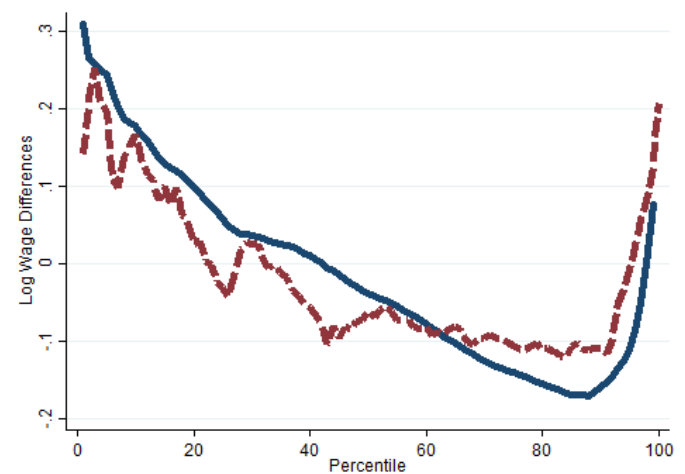

Figure A.3: *

$1995-2002$

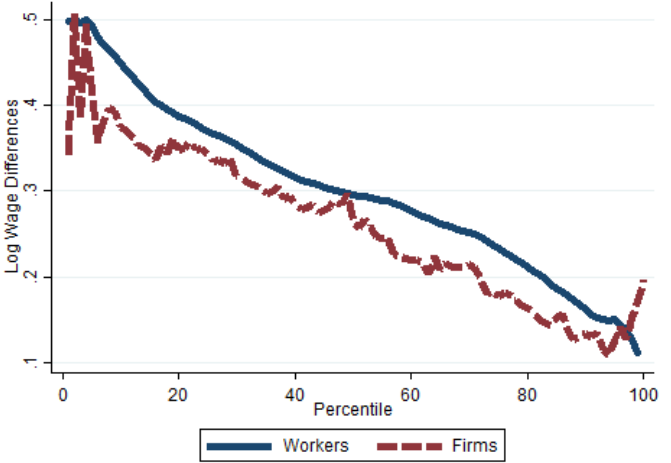

Figure A.4: *

$2003-2012$

United States ${ }^{1}$. Meanwhile, the blue solid line in the graph between 20032012 decreases in the whole distribution. Another significant difference is that between 1995-2002, the upper middle part of the distribution has real wage losses, while between 2003-2012 the whole distribution has real gains.

Between 1995-2002 the decrease in wage variance is correlated with firm size. Wage variance decreases almost exclusively in firms with less than 50 workers, which represent slightly more than $40 \%$ of the formal sector in Brazil. These results are shown in figure A.5 which plots the total (blue solid line), between (green dotted line) and within (red dashed line) variance by firm size.

To understand better what happened in the whole distribution for each size group I also plot the percentile analysis for different firm sizes during the 1995-2002 period in figure A.11. In the larger firms the polarization process is notable, with wages in the middle of the distribution having a big loss relative to wages in the bottom and top of the distribution whereas in the smaller firms there doesn't appear to be a polarization in the labor market.

In the second period, from 2003 to 2012, there are no correlations between the reduction of wage variance and firm size. Variance reduces in all firm sizes, including the larger ones. This is consistent with the fact that the wage growth during this period declines monotonically with the percentile of the distribution.

Observing all the percentiles of the distribution by firm size, the results are different from the 1995-2012 period. Figure A.23 shows that wage growth declines monotonically with the percentile of the distribution in all firm sizes, thereby there is no suggestion of polarization in the labor market during the period.

${ }^{1}$ see (26) and (27) for more details about what happened in the U.S. 
Figure A.5: Variance by firm size 1995-2002

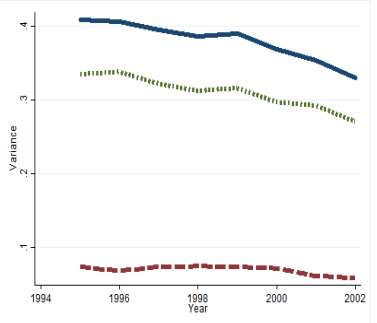

Figure A.6: *

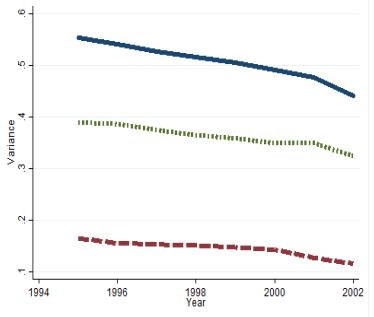

Figure A.7: * 10 to 49 workers

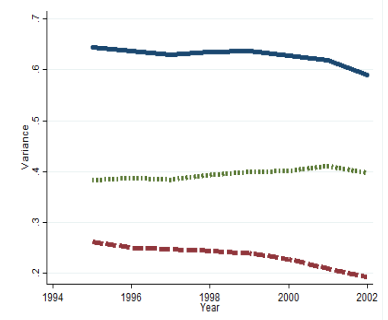

Figure A.8: * 50 to 249 workers

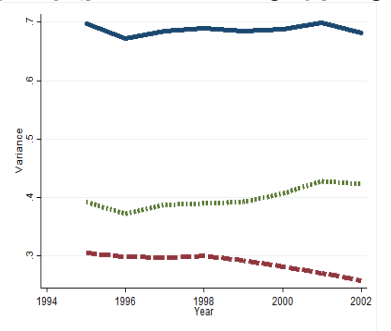

Figure A.9: * 250 to 999 workers

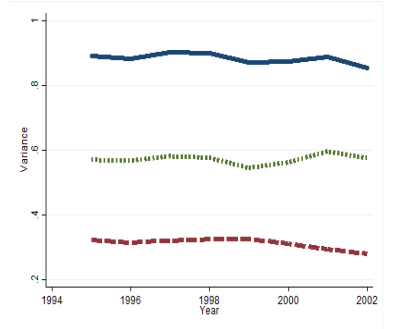

Figure A.10: *

1000 or more workers

Figure A.11: Wage growth by percentile for each firm size between 1995 and 2002

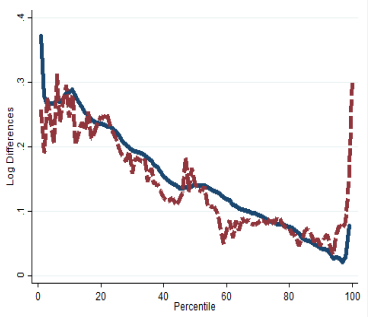

Figure A.12: * 1 to 9 workers

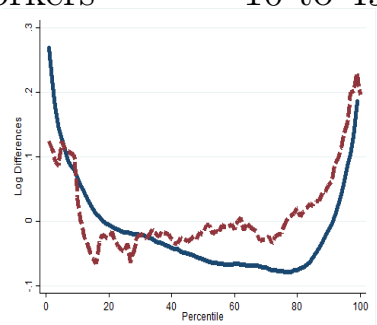

Figure A.15: * 250 to 999 workers

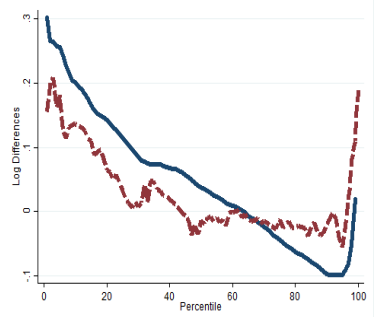

Figure A.13: * 10 to 49 workers

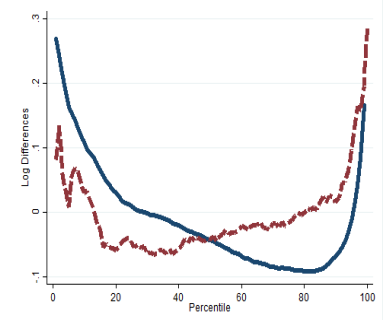

Figure A.14: * 50 to 249 workers

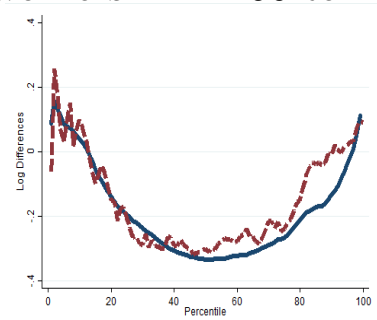

Figure A.16: * 1000 or more workers 
Figure A.17: Variance by firm size 2003-2012
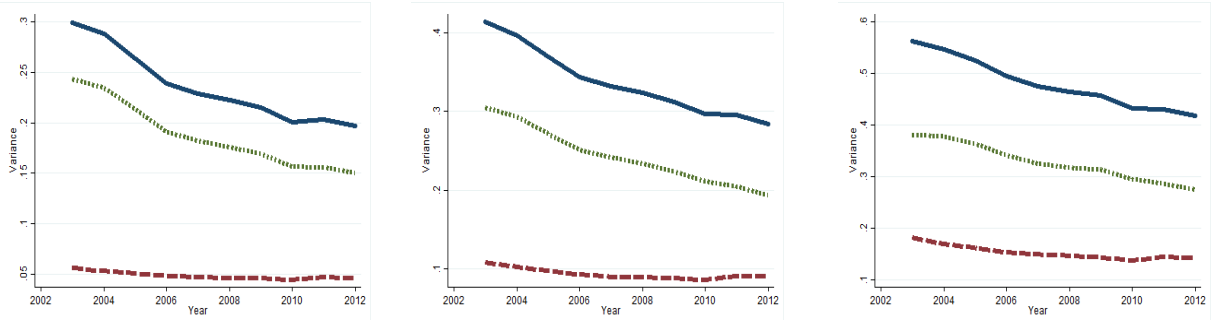

Figure A.18: *

Figure A.19: *

Figure A.20: *

1 to 9 workers

10 to 49 workers

50 to 249 workers

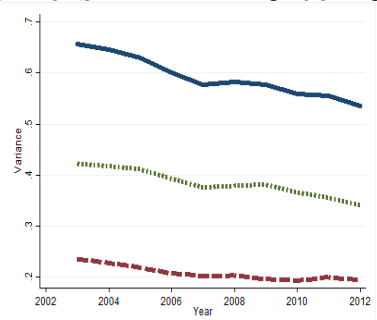

Figure A.21: * 250 to 999 workers

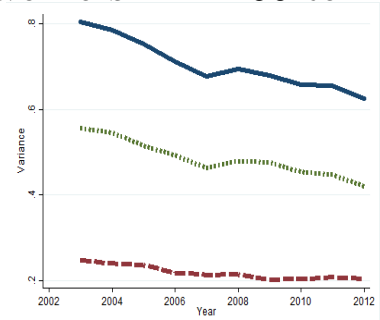

Figure A.22: *

1000 or more workers

Figure A.23: Wage growth by percentile for each firm size between 2003 and 2012

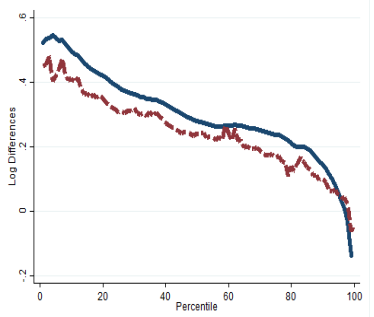

Figure A.24: * 1 to 9 workers

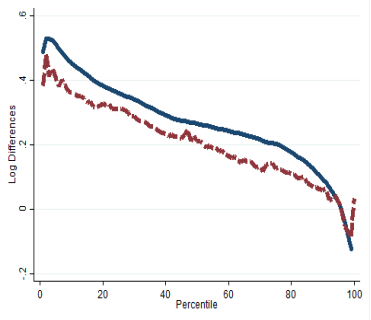

Figure A.25: * 10 to 49 workers

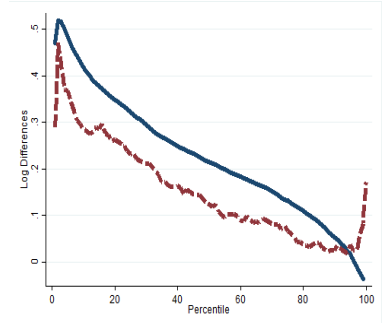

Figure A.26: * 50 to 249 workers

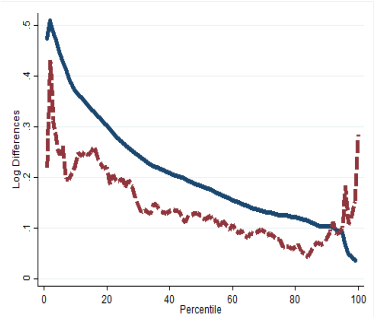

Figure A.27: * 250 to 999 workers

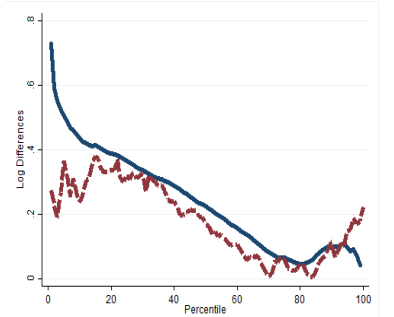

Figure A.28: * 1000 or more workers 
Figure A.29: Informality, Unemployment and Minimum Wage

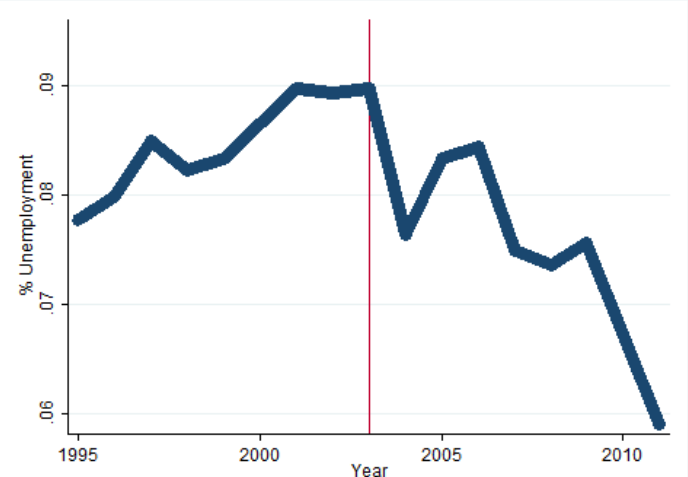

Figure A.30: *

Unemployment

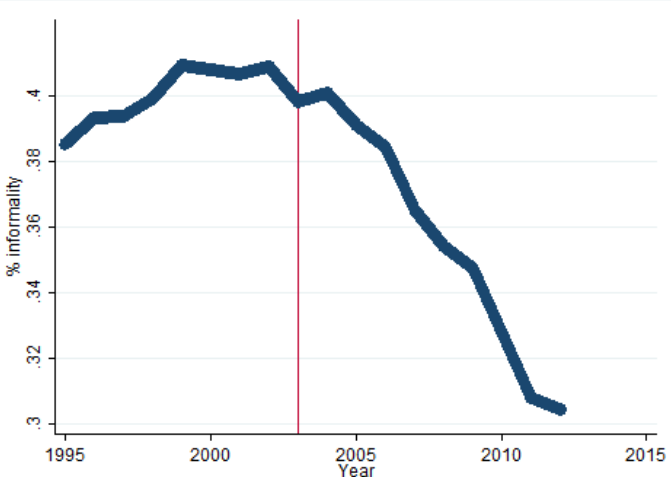

Figure A.31: * Informality

Finally, Informality and Unemployment had very different trends between both periods. The vertical line in figure A.29 divides both graphs in the periods before and after 2003. It is clear that in the first period both unemployment and informality increased, while in the second one, both decrease.

These descriptive statistics strongly suggest that the reduction of inequality from 1995 to 2012 wasn't a single process. Thus, given the complexity of analyzing the two different periods, I chose the period from 2003 to 2012. This period was chosen fist because of its recency. But also it had a more pronounced decrease of inequality, and more interesting dynamics, specially the rise of minimum wage and decreases in informality and unemployment. 
B

\section{Solving the problem of the Firm}

The problem of the firm is:

$$
\begin{gathered}
\Pi_{p}=\max _{j \in\{\text { for,inf }\}} \Pi_{p, j}(N), \text { where } \\
\Pi_{p, j}(N)=\max _{V}\left(\frac{1}{1+r d t}\right)\left\{\pi_{j}(N, V ; p) d t+\Pi_{p, j}\left(N^{\prime}\right)\right\} \\
\text { s.t. } \quad n_{i}^{\prime}=n_{i}+\dot{n}_{i} d t=\left(1-s_{i}^{j} d t\right) n_{i}+v_{i} q\left(\theta_{i}\right)
\end{gathered}
$$

The value function of each sector $\Pi_{p, j}(N)$ is solved as an usual dynamic optimization problem by taking the derivatives of the control variables to find the first order condition, and the derivatives of the state variables to find the envelop theorem.

As said in section 3 , for notation purposes I define $J_{i}^{j}(N ; p)=\frac{\partial \Pi^{j}(N ; p)}{\partial n_{i}}$. The optimality of the controls $(V)$ determines that:

$$
-\xi_{i}^{\prime}\left(v_{i}\right)+q\left(\theta_{i}\right) J_{i}^{j}\left(N^{\prime} ; p\right)=0
$$

Meanwhile, differentiating the value function on the state variable $(N)$ provides:

$$
(1+r d t) J_{i}^{j}(N ; p)=\frac{\partial \pi^{p, j}}{\partial n_{i}}+\left(1-s^{j} d t\right) J_{i}^{j}\left(N^{\prime} ; p\right)
$$

The equations presented in section 3 that characterize the steady state solution depend on the solution to $\frac{\partial \pi^{p, j}}{\partial n_{i}}$ and on the fact that in steady state equilibrium the number of workers from each type is constant in each firm $\left(n_{i}^{\prime}=n_{i}\right)$. 


\section{C \\ Solving for the Wage Function}

In this section of the appendix I show how I arrive in the wage function. The following exposition follows (14) and (13). I will present only the solution for the wage function of the formal sector. The solution to the wage function of the informal sector is the same. It is only necessary to replace $H(N ; p)==$ $F(N ; p)-\rho(N)$ and $\tau=0$.

To arrive at the wage function is necessary to combine the Nash sharing rule with the optimality condition that is derived from the envelop theorem and the value of being employed for a worker.

Nash Sharing rule

$$
\left(1-\sigma_{i}\right)\left[E_{i}^{j}\left(w_{i}^{p}(N ; p)\right)-U_{i}\right]=\sigma_{i} J_{i}^{j, p}(N)
$$

Optimality Condition from the envelop theorem

$$
\left(r+s^{f o r}\right) J_{i}^{f o r}(N ; p)=\frac{\partial F(N ; p)}{\partial n_{i}}-(1+\tau)\left[w_{i}^{f o r}(N ; p)+\sum_{l \in\{1,2,3\}} n_{l} \frac{\partial w_{l}^{f o r}(.)}{\partial n_{i}}\right]
$$

Value of being employed ( formal sector)

$$
r E_{i}^{f o r}(w)=w+s^{f o r}\left[U_{i}-E_{i}^{f o r}(w)\right]
$$

Substituting the value of being employed in the formal sector and the optimality condition in the Nash sharing rule, I find the following system of non linear differential equations. ( it is a system of three equations indexed by i)

$$
\left(1-\sigma_{i}\right)\left[\frac{w+s^{f o r} U_{i}}{\left(r+s^{\text {for }}\right)}-U_{i}\right]=\frac{\sigma_{i}}{\left(r+s^{f o r}\right)}\left\{\frac{\partial F(N ; p)}{\partial n_{i}}-(1+\tau)\left[w_{i}^{f o r}(N ; p)+\sum_{l \in\{1,2,3\}} n_{l} \frac{\partial w_{l}^{f o r}(.)}{\partial n_{i}}\right]\right\}
$$

To simplify the notation, I define $c_{i}=\left[\left(1-\sigma_{i}\right)+\sigma_{i}(1+\tau)\right]$. I simplify the above equation as: 


$$
c_{i} w_{i}(N ; p)=\left(1-\sigma_{i}\right) r U_{i}+\sigma_{i}\left[\frac{\partial F(N ; p)}{\partial n_{i}}-(1+\tau) \sum_{l \in\{1,2,3\}} n_{l} \frac{\partial w_{l}^{f o r}(.)}{\partial n_{i}}\right]
$$

To solve for this system of three equations, indexed by $i$, I take the partial derivative of the equation above for a given $i$ with respect to the labor input $k$, where $k \neq i$. This results in the following equation (indexed by $i$ and $k$ )

$$
c_{i} \frac{\partial w_{i}(N ; p)}{\partial n_{k}}=\sigma_{i} \frac{\partial^{2}}{\partial n_{i} n_{k}}\left(F(N ; p)-(1+\tau) \sum_{l \in\{1,2,3\}} n_{l} w_{l}(N ; p)\right)
$$

The system of equations have a series of symmetric terms that can be eliminated by taking the differences between the equations. This leads to:

$$
\frac{\partial w_{k}}{\partial n_{i}}=\frac{\sigma_{k}}{1-\sigma_{k}} \frac{1-\sigma_{i}}{\sigma i} \frac{\partial w_{i}}{\partial n_{k}}, \quad \forall \quad i, k=1,2,3
$$

Writing $\mathcal{X}_{i k}=\frac{\sigma_{k}}{1-\sigma_{k}} \frac{1-\sigma_{i}}{\sigma i}$, implies that:

$$
\sum_{l \in\{1,2,3\}} n_{l} \frac{\partial w_{l}(.)}{\partial n_{i}}=\sum_{l \in\{1,2,3\}} \mathcal{X}_{i l} n_{l} \frac{\partial w_{i}(.)}{\partial n_{l}}
$$

This allows me to rewrite the original system of equations as:

$$
c_{i} w_{i}(N ; p)=\left(1-\sigma_{i}\right) r U_{i}+\sigma_{i}\left[\frac{\partial F(N ; p)}{\partial n_{i}}-(1+\tau) \sum_{l \in\{1,2,3\}} \mathcal{X}_{i l} n_{l} \frac{\partial w_{i}(.)}{\partial n_{l}}\right]
$$

I follow (14) and first solve the problem when $\mathcal{X}_{i k}=1$. Later I generalize the solution. Their insight is to write the system above in a different system of coordinates. This will simplify the system to a univariate differential equation. The labor inputs are written in a generalized spheric coordinates, where $\rho$ is the distance to the origin, and $\phi_{i}, \quad i \in\{1,2\}$ are the angles of projection in different subplanes. Thus, the labor inputs are substituted by:

$$
\begin{aligned}
& n_{1}=\rho \cos \phi_{1} \cos \phi_{2} \\
& n_{2}=\rho \cos \phi_{1} \sin \phi 1 \\
& n_{3}=\rho \sin \phi_{1} \sin \phi_{2}
\end{aligned}
$$

The economic interpretation of this notation is that $\rho$ denotes the scale of use of the labor inputs whereas $\phi_{i}$ their proportions. With this changes of coordinates, new wage and production functions will be necessary. They are a 
transformation of the former functions of $n_{1}, n_{2}, n_{3}$ to functions of $\rho, \phi_{1}, \phi_{2}{ }^{1}$, such that it is possible to write the term multiplying $(1+\tau)$ as:

$$
\sum_{l \in\{1,2,3\}} n_{l} \frac{\partial w_{i}(.)}{\partial n_{l}}=\rho \frac{\partial w_{i}\left(\rho, \phi_{1}, \phi_{2}\right)}{\partial \rho}
$$

Then I can rewrite the differential equation as:

$$
\frac{\partial \hat{w}_{i}\left(\rho, \phi_{1}, \phi_{2}\right)}{\partial \rho}+\frac{c_{i} \hat{w}_{i}\left(\rho, \phi_{1}, \phi_{2}\right)}{\rho \sigma_{i}(1+\tau)}=\frac{\left(1-\sigma_{i}\right) U_{i}}{\rho \sigma_{i}(1+\tau)}+\frac{1}{\rho(1+\tau)} \frac{\partial \hat{F}\left(\rho, \phi_{1}, \phi_{2}\right)}{\partial n_{i}}
$$

Following (14), the solution guessed to this problem takes the following form:

$$
\begin{gathered}
\hat{w}_{i}\left(\rho, \phi_{1}, \phi_{2}\right)=C\left(\rho, \phi_{1}, \phi_{2}\right) \rho^{-\frac{c_{i}}{\sigma_{i}(1+\tau)}}+D(\phi) \\
\frac{\left.\partial \hat{w}_{i}\left(\rho, \phi_{1}, \phi_{2}\right)\right)}{\partial \rho}=\frac{\partial C\left(\rho, \phi_{1}, \phi_{2}\right)}{\partial \rho} \rho^{-\frac{c_{i}}{\sigma_{i}(1+\tau)}}-C\left(\rho, \phi_{1}, \phi_{2}\right) \frac{c_{i}}{\sigma(1+\tau)} \rho^{-\frac{c_{i}}{\sigma_{i}(1+\tau)}-1}
\end{gathered}
$$

Now, replacing these guesses on the left side of the differential equation, I obtain:

$$
\frac{\partial C\left(\rho, \phi_{1}, \phi_{2}\right)}{\partial \rho} \rho^{-\frac{c_{i}}{\sigma_{i}(1+\tau)}}-C\left(\rho, \phi_{1}, \phi_{2}\right) \frac{c_{i}}{\sigma(1+\tau)} \rho^{-\frac{c_{i}}{\sigma_{i}(1+\tau)}-1}+\frac{c_{i}}{\rho \sigma_{i}(1+\tau)}\left(C\left(\rho, \phi_{1}, \phi_{2}\right) \rho^{-\frac{c_{i}}{\sigma_{i}(1+\tau)}}+D(\phi)\right)
$$

Simplifying the equation above, and writing the right side of the differential equation provides me:

$\frac{\partial C\left(\rho, \phi_{1}, \phi_{2}\right)}{\partial \rho} \rho^{-\frac{c_{i}}{\sigma_{i}(1+\tau)}}+\frac{c_{i}}{\rho \sigma_{i}(1+\tau)} D(\phi)=\frac{\left(1-\sigma_{i}\right) U_{i}}{\rho \sigma_{i}(1+\tau)}+\frac{1}{\rho(1+\tau)} \frac{\partial \hat{F}\left(\rho, \phi_{1}, \phi_{2}\right)}{\partial n_{i}}$

This gives me the following expressions for the functions $\frac{\partial C\left(\rho, \phi_{1}, \phi_{2}\right)}{\partial \rho}$ and $D(\phi)$ :

$$
\begin{gathered}
D(\phi)=\frac{\left(1-\sigma_{i}\right) U_{i}}{c_{i}} \\
\frac{\partial C\left(\rho, \phi_{1}, \phi_{2}\right)}{\partial \rho}=\rho^{\frac{c_{i}}{\sigma_{i}(1+\tau)}} \frac{\partial \hat{F}\left(\rho, \phi_{1}, \phi_{2}\right)}{\partial n_{i}}
\end{gathered}
$$

Integrating $\frac{\partial C\left(\rho, \phi_{1}, \phi_{2}\right)}{\partial \rho} \mathrm{I}$ arrive at:

\footnotetext{
${ }^{1}$ These new functions will be written as: $\hat{w}_{i}\left(\rho, \phi_{1}, \phi_{2}\right)=w_{i}\left(n_{1}, n_{2}, n_{3}\right)$ and $\hat{F}\left(\rho, \phi_{1}, \phi_{2}\right)=$ $F\left(n_{1}, n_{2}, n_{3}\right)$
} 


$$
C\left(\rho, \phi_{1}, \phi_{2}\right)=\frac{1}{1+\tau} \int_{0}^{\rho} z^{\frac{c_{i}}{\sigma_{i}(1+\tau)}} \frac{\partial \hat{F}\left(z, \phi_{1}, \phi_{2}\right)}{\partial n_{i}} d z+\kappa(\phi)
$$

This allows me to write the wage function $\hat{w}_{i}\left(\rho, \phi_{1}, \phi_{2}\right)$ as :

$$
\hat{w}_{i}\left(\rho, \phi_{1}, \phi_{2}\right)=\frac{\left(1-\sigma_{i}\right) U_{i}}{c_{i}}+\frac{\rho^{-\frac{c_{i}}{\sigma_{i}(1+\tau)}}}{1+\tau} \int_{0}^{\rho} z^{\frac{c_{i}}{\sigma_{i}(1+\tau)}} \frac{\partial \hat{F}\left(z, \phi_{1}, \phi_{2}\right)}{\partial n_{i}} d z+\kappa(\phi)
$$

It is still necessary to pin down the integration constant $\kappa(\phi)$. Following (14) , I assume that $\lim _{\rho \rightarrow 0} \rho \hat{w}_{i}\left(\rho, \phi_{1}, \phi_{2}\right)=0$. In economic terms, this assumption is very reasonable as it implies that when firms decrease its size keeping their share of workers from each type constant, the payroll goes to zero. The validity of this assumption depends on $\frac{1}{\rho}$ increasing as $\rho \rightarrow 0$ faster than the marginal productivities. This is valid for our CES functional form. With this assumption, $\kappa(\phi)=0$

To go back to the original production function written as a function of labor inputs, I first write $x=\frac{z}{\rho}$. Than I can equal $\frac{\partial \hat{F}\left(z, \phi_{1}, \phi_{2}\right)}{\partial n_{i}}=\frac{\partial \hat{F}\left(x \rho, \phi_{1}, \phi_{2}\right)}{\partial n_{i}}=$ $\frac{\partial F\left(x n_{1}, x n_{2}, x n_{3}\right)}{\partial n_{i}}$. Then the wage function as a function of the labor inputs can be written as:

$$
w_{i}(N)=\frac{\left(1-\sigma_{i}\right) U_{i}}{c_{i}}+\frac{1}{1+\tau} \int_{0}^{1} x^{\frac{c_{i}}{\sigma_{i}(1+\tau)}} \frac{\partial F\left(x n_{1}, x n_{2}, x n_{3}\right)}{\partial n_{i}} d x
$$

This is the solution for when $\mathcal{X}_{i k}=1$. To extend it to cases where this equality doesn't hold, it is necessary to introduce a new set of variables $\mathcal{M}_{i}=\left(M_{i 1}, M_{i 2}, M_{i 3}\right)$. This variables are such that they equal:

$$
\sum_{j \in\{1,2,3\}} M_{i j} \frac{\partial \nu_{j}\left(\mathcal{M}_{i}\right)}{\partial M_{i j}}=\sum_{j \in\{1,2,3\}} \mathcal{X}_{i j} n_{j} \frac{\partial w_{i}(N)}{\partial n_{j}}
$$

where $\nu_{j}\left(\mathcal{M}_{i}\right)=w_{i}(N)$. To find the variables $\mathcal{M}_{>}$as a function of $N$, lets assume a simpler form where $M_{i l}=M_{i l}\left(n_{l}\right)$ ( only a function of one labor input). Then, it is only necessary to have:

$$
M_{i l} \frac{\partial \nu_{j}\left(\mathcal{M}_{i}\right)}{\partial M_{i j}}=\mathcal{X}_{i j} n_{j} \frac{\partial w_{i}(N)}{\partial n_{j}}
$$

Since by the definition of $\nu_{i}\left(\mathcal{M}_{i}\right)$ :

$$
\frac{\partial w_{i}(N)}{\partial n_{j}}=\frac{\partial \nu_{j}\left(\mathcal{M}_{i}\right)}{M_{i j}} \frac{d M_{i j}}{n_{j}}
$$

It gives me a differential equation for $M_{i j}$ : 


$$
M_{i j}=\mathcal{X}_{i j} n_{j} \frac{d M_{i j}}{d N_{j}}
$$

Which needs only one solution. The simplest one is:

$$
M_{i j}=n_{j}^{\frac{1}{\mathcal{X}_{i j}}}=n_{j}^{\mathcal{X}_{j i}}
$$

Now, denoting the production function in this new coordinate system as $\tilde{F}\left(\mathcal{M}_{i}\right)=F(N)$, and using the fact that $\frac{\partial F(N)}{\partial n_{j}}=\mathcal{X}_{j i} n_{j}^{\mathcal{X}_{j i}-1} \frac{\partial \tilde{F}\left(\mathcal{M}_{i}\right)}{\partial M_{i i}}$ the system of equations for the functions $\nu_{i}\left(\mathcal{M}_{i}\right)$ can be rewritten as:

$$
\nu_{i}\left(\mathcal{M}_{i}\right)=\frac{\left(1-\sigma_{i}\right) U_{i}}{c_{i}}+\sigma_{i}\left[\frac{\partial \tilde{F}\left(\mathcal{M}_{i}\right)}{\partial M_{i i}}-(1+\tau) \sum_{j \in\{1,2,3\}} M_{j} \frac{\partial \nu_{i}\left(\mathcal{M}_{i}\right)}{\partial M_{i j}}\right]
$$

Which is equivalent to the system solved above. Thus, the solution for $\nu_{i}$ is:

$$
\nu_{i}\left(\mathcal{M}_{i}\right)=\frac{\left(1-\sigma_{i}\right) U_{i}}{c_{i}}+\frac{1}{1+\tau} \int_{0}^{1} x^{\frac{c_{i}}{\sigma_{i}(1+\tau)}} \frac{\partial \tilde{F}\left(x M_{i 1}, x M_{i 2}, x M_{i 3}\right)}{\partial M_{i i}} d x
$$

Now, going back to the original coordinates, and inputting the productivity index again, the wage function that is used in the paper is:

$$
w_{i}(N ; p)=\frac{1-\sigma_{i}}{c_{i}} r\left(U_{i}\right)+\frac{1}{1+\tau} \int_{0}^{1} x^{\frac{1-\sigma}{\sigma(1+\tau)}} \frac{\partial F^{p}\left(A_{i}(x) N\right)}{\partial n_{i}} d x
$$

where $A_{i}(x)$ is a $3 \times 3$ diagonal matrix where each entry is $x^{\frac{1-\sigma_{i}}{\sigma_{i}} \frac{\sigma_{k}}{1-\sigma_{k}}} \quad k \in$ $\{1,2,3\}$. 